\title{
J. L. MACKIE, “CAUSAS Y CONDICIONES"
}

\section{Título original: "Causes and Conditions", American Philosophical Quar- terly, Vol. 2, No. 4, Octubre de 1965, pp. 245-264}

\section{Traducción $^{1}$ : Ezequiel Zerbudis}

Si nos preguntan qué es una causa, podemos estar tentados a decir que es un evento que precede al evento del que es causa, y que es tanto necesario como suficiente para la ocurrencia de éste último; resumidamente, que una causa es una condición precedente necesaria y suficiente. Hay, sin embargo, muchas dificultades con esta explicación. Intentaré mostrar que lo que a menudo llamamos una causa es una condición, no de este tipo, sino de un tipo relacionado con éste. Es decir, esta explicación necesita una modificación, y puede ser modificada, y cuando se la modifica podemos explicar de una manera mucho más satisfactoria cómo es que podemos llegar a una buena cantidad de lo que ordinariamente consideramos como conocimiento causal; las afirmaciones implícitas en nuestras aseveraciones causales pueden relacionarse con las formas de la evidencia sobre la que a menudo nos apoyamos cuando aseveramos una conexión causal.

\section{Enunciados causales singulares.}

Supongamos que se inicia un incendio en cierta casa, pero que ha sido extinguido antes de que la casa fuera destruida completamente. Los expertos investigan la causa del incendio, y concluyen que fue causado por un cortocircuito eléctrico en un cierto lugar. ¿Cuál es la fuerza exacta de su afirmación de que este cortocircuito causó este incendio?

\footnotetext{
${ }^{1}$ Esta traducción, realizada por E. Zerbudis, se publica aquí con la autorización del American Philosophical Quarterly y de los herederos de J. L. Mackie
} 
Claramente, los expertos no están diciendo que el cortocircuito fue una condición necesaria para que la casa se prendiera fuego en ese momento; ellos saben perfectamente bien que un cortocircuito en algún otro lugar, o que se volcara un hornillo de aceite encendido, o una gran cantidad de otras cosas podrían, si hubieran ocurrido, haber incendiado la casa. Del mismo modo, no están diciendo que el cortocircuito era una condición suficiente para que esta casa se prendiera fuego; pues si el cortocircuito hubiera ocurrido, pero no hubiera habido ningún material inflamable alrededor, el incendio no se habría iniciado y, aún dados tanto el cortocircuito como el material inflamable, el incendio no habría ocurrido si, digamos, hubiera habido en el lugar apropiado un rociador automático eficiente. Lejos de ser una condición tanto necesaria como suficiente para el incendio, el cortocircuito no fue ni necesario ni suficiente para que ocurriera, y los expertos saben que esto era así. ¿En qué sentido, entonces, se dice que causó el incendio?

Al menos una parte de la respuesta es que hay un conjunto de condiciones (de las cuales algunas son positivas y otras negativas), que incluyen la presencia de material inflamable, la ausencia de un rociador localizado apropiadamente, y sin duda un buen número de otras, las cuales, combinadas con el cortocircuito, constituyeron una condición compleja que fue suficiente para que la casa se prendiera fuego - suficiente, pero no necesaria, ya que el incendio podría haber comenzado de otras maneras. Además el cortocircuito era una parte indispensable de esta condición compleja: las otras partes de esta condición, en conjunción unas con las otras pero en ausencia del cortocircuito, no habrían producido el incendio. El cortocircuito del que se dice que causó el incendio es así una parte indispensable de una condición compleja suficiente (pero no necesaria) del incendio. En este caso, entonces, la así llamada causa es, y se sabe que es, una parte insuficiente pero necesaria de una condición que es ella misma innecesaria pero suficiente para el resultado. Los expertos dicen, en efecto, que el cortocircuito es una condición de este tipo, que ocurrió, que las otras condiciones que juntamente con él forman una condición suficiente también estaban presentes, y que ninguna otra condición suficiente para que la casa se prendiera fuego estaba presente en esta ocasión. Sugiero que cuando hablamos de la causa de un evento particular, a menudo lo que se tiene en mente es una condición de este tipo. Teniendo en cuenta la importancia de las condiciones de este tipo en nuestro conocimiento y nuestro discurso acerca de la causación, será conveniente tener 
un nombre breve para ellas: llamemos a una condición semejante una condición INIS (sobre la base de las iniciales de las palabras resaltadas más arriba). ${ }^{2}$

Esta explicación de la fuerza de la afirmación de los expertos acerca de la causa del incendio puede ser confirmada si reflexionamos acerca de la manera en que puede suponerse que llegaron a esa conclusión, y acerca de la manera en la que quien estuviera en desacuerdo con ella debería ponerla en duda. Una parte importante de la investigación habrá consistido en rastrear el curso efectivo del incendio; los expertos habrán determinado que ninguna otra condición suficiente para que se iniciase el incendio, y para que tomara ese curso, estaba presente, pero que el cortocircuito sí ocurrió y que había condiciones presentes que en conjunción con él fueron suficientes para que el incendio se iniciara y tomara el curso que tomó. Suponiendo que hay alguna condición necesaria y suficiente del incendio - y esta es una suposición que comúnmente hacemos en tales contextos - quien quisiera negar la conclusión de los expertos tendría que poner en duda uno u otro de estos puntos.

Podemos dar un análisis más formal de la afirmación de que algo es una condición INIS. Supongamos que ' $A$ ' refiere a la condición INIS - en nuestro ejemplo, la ocurrencia del cortocircuito en ese lugar $-\mathrm{y}$ que ' $B$ ' y ' $\neg C$ ' (esto es, 'no- $C$ ', o la ausencia de $C$ ) refieren a las otras condiciones, tanto positivas como negativas, que resultan necesarias, junto con $A$, para formar una condición suficiente para el incendio - en nuestro ejemplo, $B$ podría ser la presencia de material inflamable, $\neg C$ la ausencia de un rociador apropiadamente localizado. Entonces, la conjunción ' $A B \neg C$ ' representa una condición suficiente del incendio, y una que no contiene factores redundantes; esto es, $A B \neg C$ es una condición suficiente mínima para el incendio. ${ }^{3}$ De manera similar, sean $D \neg E F, \neg G \neg H I$, etc., todas las otras condiciones suficientes mínimas de este resultado. Ahora bien, suponiendo que hay alguna condición necesaria y suficiente para este resultado, la disyunción de todas las

\footnotetext{
${ }^{2}$ Este término fue sugerido por D. C. Stove, quien también me ha ayudado mucho al criticar versiones previas de este artículo.

${ }^{3}$ La frase "condición suficiente mínima" la tomo de Konrad Marc-Wogau, "On Historical Explanation”, Theoria, vol. 28 (1962), pp. 213-233. Este artículo ofrece un análisis de los enunciados causales singulares, con referencia especial a su uso por parte de los historiadores, que es sustancialmente equivalente a la explicación que estoy sugiriendo. Hago muchas otras referencias a este artículo, especialmente en la n. 9 más abajo.
} 
condiciones suficientes mínimas para que éste se dé constituye una condición necesaria y suficiente. ${ }^{4}$ Esto es, la fórmula “ $A B \neg C$ o $D \neg E F$ o $\neg G \neg H I$ o ..." representa una condición necesaria y suficiente para el incendio, cada uno de sus disyuntos, tales como ' $A B \neg C$ ', representa una condición suficiente mínima, y cada término de la conjunción en cada condición suficiente mínima, tal como ' $A$ ', representa una condición INIS. Para simplificar y generalizar esto, podemos reemplazar la conjunción de términos conjuntados con ' $A$ ' (aquí ' $B \neg C$ ') por el término único ' $X$ ', y la fórmula que representa la disyunción de todas las otras condiciones suficientes mínimas - aquí, “ $D \neg E F$ o $\neg G \neg H I$ o ..." - por el término único ' $Y$ '. Entonces, una condición INIS se define como sigue:

$A$ es una condición INIS de un resultado $F$ si y sólo si, para algún $X$ y para algún $Y,(A X \circ Y)$ es una condición necesaria y suficiente para $F$, pero $A$ no es una condición suficiente para $F$ y $X$ no es una condición suficiente para $F$.

Podemos indicar este tipo de relación más brevemente si damos por supuestas las condiciones y reemplazamos las variables existencialmente cuantificadas ' $X$ ' e ' $Y$ ' por

${ }^{4}$ Cf. la n. 8 en la p. 227 del artículo de Marc-Wogau, en la que se señala que para inferir que la disyunción de todas las condiciones suficientes mínimas será una condición necesaria, "es necesario presuponer que un evento arbitrario $C$, si ocurre, debe tener una razón suficiente para ocurrir". Esta presuposición es equivalente a la presuposición de que hay alguna condición (posiblemente compleja) que es a la vez necesaria y suficiente para $C$.

Es de cierto interés que algunos giros lingüísticos corrientes expresan esta presuposición. Decir "Nada sino $X$ resultará suficiente", u "O bien $X$ o bien $Y$ resultarán suficientes, pero ninguna otra cosa lo hará", es una manera natural de decir que $X$, o la disyunción $(X \circ Y)$, es una condición necesaria para cualquier resultado que tengamos en mente. Pero tomadas de manera literal estas observaciones sólo dicen que no hay ninguna condición suficiente para este resultado distinta de $X$, o distinta de la conjunción $(X \circ Y)$. Esto es, usamos para significar "una condición necesaria" frases cuyos significados literales serían "la única condición suficiente" o "la disyunción de todas las condiciones suficientes" De manera similar, decir que $Z$ es "todo lo que se necesita" es una manera natural de decir que $Z$ es una condición suficiente, pero tomada literalmente esta observación dice que $Z$ es la única condición necesaria. Pero, una vez más, que la única condición necesaria será también una condición suficiente se sigue sólo si presuponemos que alguna condición es tanto necesaria como suficiente. 
puntos. Esto es, podemos decir que $A$ es una condición INIS de $F$ cuando $(A \ldots$ o ...) es una condición necesaria y suficiente para $F$.

(Para anticiparme a posibles malos entendidos, completaría esta definición como sigue. ${ }^{5}$ En primer lugar, podría haber un conjunto de condiciones suficientes mínimas de $F$, pero ninguna condición necesaria, ni siquiera una compleja; en semejante caso, $A$ podría ser lo que Marc-Wogau llama un momento en una condición suficiente mínima, pero yo no la llamaré una condición INIS. Sólo hablaré de una condición INIS cuando la disyunción de todas las condiciones suficientes mínimas también es una condición necesaria. En segundo lugar, la definición deja abierto que la condición INIS $A$ pudiera ser un término de la conjunción en cada una de las condiciones suficientes mínimas. Si es así, $A$ sería ella misma una condición necesaria del resultado. Seguiré llamando a $A$ una condición INIS en estas circunstancias: no es parte de la definición de una condición INIS que no sea necesaria, aunque en los casos típicos, tales como el presentado más arriba, de hecho no es necesaria. ${ }^{6}$ En tercer lugar, el requisito de que $X$ por sí misma no fuera suficiente para $F$ asegura que $A$ es una parte no redundante de la condición suficiente $A X$; pero hay un sentido en el que puede no ser estrictamente necesaria o indispensable siquiera como una parte de esta condición, ya que puede ser reemplazable: por ejemplo, $K X$ podría ser otra condición suficiente mínima de $F{ }^{7}$ En cuarto lugar, es parte de la definición que la condición suficiente mínima, $A X$, de la que $A$ es una parte no redundante, no sea también una condición necesaria, que hay otra condición suficiente $Y$ (que puede ser ella misma una disyunción de condiciones suficientes). En quinto lugar, y de manera similar, es parte de la definición que $A$ no es por sí misma suficiente para $F$. Los puntos cuarto y quinto equivalen a esto: llamaré a $A$ una condición INIS sólo si hay términos que efectivamente ocupan los lugares ocupados por ' $X$ ' e ' $Y$ ' en la fórmula para la condición necesaria y suficiente. Sin embargo, puede haber casos en los que hay sólo una condición suficiente mínima, digamos,

\footnotetext{
${ }^{5}$ Estoy en deuda con los árbitros de la revista [donde se publicó originalmente este artículo] por sugerir que estos puntos sean clarificados.

${ }^{6}$ Casos especiales en los que una condición INIS es también una condición necesaria son mencionados al final de $\S 3$.

${ }^{7}$ Este punto, y el término "no redundante", son tomados de la reseña de Michael Scriven de The Structure of Science de Nagel, en Review of Metaphysics, 1964. Véase especialmente el pasaje en la p. 408 citado más abajo.
} 
$A X$. Además, puede haber casos donde $A$ es ella misma una condición suficiente, siendo ( $A$ o $Y$ ) la disyunción de todas las condiciones suficientes mínimas; además, puede haber casos en los que $A$ misma es la única condición suficiente mínima, y es ella misma tanto necesaria como suficiente para $F$. En cualquiera de estos casos, así como en casos en los que $A$ es una condición INIS, diré que $A$ es al menos una condición INIS. Como veremos, a menudo tenemos evidencia que respalda la conclusión de que algo es al menos una condición INIS; podemos tener o no evidencia adicional que muestre que no es más que una condición INIS.)

Sugiero que un enunciado que afirma una secuencia causal singular, de una forma como la de " $A$ causó $F$ " a menudo hace, implícitamente, las siguientes afirmaciones:

(i) $A$ es al menos una condición INIS de $F$ - esto es, hay una condición necesaria y suficiente de $F$ que tiene una de estas formas: $(A X \circ Y),(A \circ Y), A X, A$.

(ii) $A$ estaba presente en la ocasión en cuestión.

(iii) Los factores representados por la ' $X$ ', si es que hay alguno, en la fórmula para la condición necesaria y suficiente estaban presentes en la ocasión en cuestión.

(iv) Cada disyunto de ' $Y$ ' que no contiene a ' $A$ ' como un término de la conjunción estaba ausente en la ocasión en cuestión. (En general, esto quiere decir que lo que sea que es representado por ' $Y$ ' estaba ausente en esta ocasión. $\mathrm{Si}$ ' $Y$ ' representa una única conjunción de factores, entonces estaba ausente si al menos uno de los términos de esa conjunción estaba ausente; si representa una disyunción, estaba ausente si cada uno de sus disyuntos estaba ausente. Pero no queremos excluir la posibilidad de que ' $Y$ ' sea, o contenga como un disyunto, una conjunción uno de cuyos términos es $A$, ni requerir que esta conjunción hubiera estado ausente. $)^{8}$

No estoy sugiriendo que esto es la totalidad de lo que se quiere decir mediante " $A$ causó $F$ " en cualquier ocasión, o siquiera que es una parte de lo que es significado en toda ocasión: algunas partes adicionales y alternativas del significado de tales enunciados son indicadas más abajo. ${ }^{9}$ Pero estoy sugiriendo que esta es una parte importante del concepto

\footnotetext{
${ }^{8}$ Véase el ejemplo del receptor [en el juego del críquet] discutido más abajo. ${ }^{9}$ Véanse $\S \S 7,8$.
} 
de causación; la prueba de esta sugerencia sería que en muchos casos la falsación de alguna de las afirmaciones arriba mencionadas refutaría la aserción de que $A$ causó $F$.

Esta explicación concuerda en buena medida, en sustancia si no en terminología, con al menos dos explicaciones ofrecidas recientemente de la causa de un evento singular.

Konrad Marc-Wogau resume su explicación de este modo:

cuando los historiadores, en enunciados causales singulares, hablan de una causa o de la causa de un cierto evento individual $\beta$, a lo que se refieren en ese caso es a otro evento individual $\alpha$ que es un momento en una condición suficiente mínima y al mismo tiempo necesaria post factum $\beta .^{10}$

Explica su frase "condición necesaria post factum" diciendo que va a llamar a un evento $a_{1}$ una condición necesaria post factum de $x$ si la disyunción " $a_{1}$ o $a_{2}$ o $a_{3} \ldots$ o $a_{n}$ " representa una condición necesaria de $x$, y de estos disyuntos solo $a_{1}$ estaba presente en la ocasión particular en la que $x$ ocurrió.

De manera similar, Michael Scriven ha dicho:

${ }^{10}$ Véase pp. 226-227 del artículo al que nos referimos en la n. 2 más arriba. La formulación completa de Marc-Wogau es como sigue:

"Supongamos que 'csm' significa condición suficiente mínima y 'cn' condición necesaria. Entonces supongamos que tenemos una clase $K$ de eventos individuales $a_{1}, a_{2}, \ldots a_{\mathrm{n}}$. (Parece razonable suponer que $K$ es finito; sin embargo, aún si $K$ fuera infinito el razonamiento más abajo no se vería afectado). Mi análisis del enunciado causal singular: $\alpha$ es la causa de $\beta$, donde $\alpha$ y $\beta$ significan eventos individuales, puede expresarse sumariamente en los siguientes enunciados:

(1) $(E K)\left(K=\left\{a_{1}, a_{2}, \ldots a_{\mathrm{n}}\right\}\right)$;

(2) $(x)(x \in K$ ? $x \operatorname{csm} \beta)$;

(3) $\left(a_{1} \mathrm{v} a_{2} \mathrm{v} \ldots a_{\mathrm{n}}\right) \mathrm{cn} \beta$;

(4) $(x)\left(\left(x \in K x\right.\right.$ ? $\left.a_{1}\right) ? x$ no es satisfecha cuando $\alpha$ ocurre);

(5) $\alpha$ es un momento en $a_{1}$.

(3) y (4) dicen que $a_{1}$ es una condición necesaria post factum para $\beta$. Si $a_{1}$ es una condición necesaria post factum de $\beta$ entonces todo momento en $a_{1}$ es una condición necesaria post factum para $\beta$, y por lo tanto también $\alpha$. Como ya se mencionó antes (nota 6 ) se supone que hay una secuencia temporal entre $\alpha$ y $\beta ; \beta$ no es él mismo un elemento en $K^{\prime \prime}$. 
Las causas no son necesarias, ni siquiera de manera contingente, no son suficientes - pero son, para hablar ese lenguaje, contingentemente suficientes.... Son parte de un conjunto de condiciones que sí garantiza el resultado, y son no redundantes en el sentido de que el resto de este conjunto (que no incluye a todas las otras condiciones presentes) no es por sí solo suficiente para el resultado. Ni siquiera es verdadero que sean relativamente necesarias, i.e., necesarias respecto de ese conjunto de condiciones más bien que respecto de las circunstancias totales de su ocurrencia, pues puede haber diversos reemplazos posibles para ellas que de hecho no están presentes. Sigue habiendo un fantasma de necesidad; una causa es un factor de un conjunto de factores posibles la presencia de uno de los cuales (de cualquiera de ellos) es necesaria para que un conjunto de condiciones efectivamente presentes sean suficientes para el efecto. ${ }^{11}$

Hay sólo diferencias sutiles entre estas dos explicaciones, o entre cada una de ellas y la ofrecida más arriba. Scriven parece hablar de un modo demasiado fuerte cuando dice que las causas no son necesarias: en verdad, no es parte de la definición de una causa de este tipo que sea necesaria, pero, como fue notado más arriba, una causa, o una condición INIS, puede ser necesaria, ya sea porque hay una única condición suficiente mínima o porque la causa es un momento en cada una de las condiciones suficientes mínimas. Por otra parte, la explicación de Marc-Wogau de una condición suficiente mínima parece demasiado fuerte. Dice que una condición suficiente mínima contiene "sólo aquellos momentos relevantes para el efecto" y que un momento es relevante para un efecto si "es una condición necesaria para $\beta$ : $\beta$ no habría ocurrido si este momento no hubiera estado presente". Esto es menos preciso que la afirmación de Scriven de que la causa sólo necesita ser no redundante. ${ }^{12}$ También, el requisito de Marc-Wogau, en su explicación de una

\footnotetext{
${ }^{11}$ Op. cit., p. 408.

${ }^{12}$ Sin embargo, en la n. 7 en pp. 222-233, Marc-Wogau llama la atención sobre la dificultad de dar una definición precisa de "un momento en una condición suficiente". Hay complicaciones adicionales involucradas en la explicación dada en $\S 5$ más abajo de "cúmulos" de factores y la
} 
condición necesaria post factum, de que sólo una condición suficiente mínima (la que contiene a $\alpha$ ) estuviera presente en la ocasión particular, parece un poco demasiado fuerte. Si dos o más condiciones suficientes mínimas (digamos, $a_{1}$ y $a_{2}$ ) estuvieran presentes, pero $\alpha$ fuera un momento en cada una de ellas, entonces si bien ni $a_{1}$ ni $a_{2}$ eran necesarias post factum, a lo sería. Usaré esta frase, "necesario post factum" para incluir casos de este tipo: esto es, $\alpha$ es una condición necesaria post factum si es un momento en toda condición suficiente mínima que estaba presente. Por ejemplo, en un equipo de cricket el receptor es también un buen bateador. Es lesionado durante un partido, y no batea en el segundo turno, y el receptor suplente pierde una atajada vital que el receptor original habría realizado. El equipo pierde el partido, pero habría ganado si el receptor hubiera tanto bateado como realizado la atajada. Su lesión era un momento en dos condiciones suficientes mínimas para la pérdida del partido; o bien el hecho de que no bateaba, o que no se lograra la atajada, habrían asegurado por sí mismas la pérdida del partido.

Esta explicación puede ser resumida, de manera breve y aproximada, diciendo que el enunciado " $A$ causó $F$ ” a menudo afirma que $A$ era necesaria y suficiente para $F$ en las circunstancias. Esta descripción se aplica en los casos estándar, pero ya hemos notado que una causa es no redundante antes que necesaria aún en las circunstancias, y veremos que hay casos especiales en los que puede no ser ni necesaria ni no redundante.

\section{Dificultades y refinamientos. ${ }^{13}$}

Tanto Scriven como Marc-Wogau están preocupados no sólo por esta explicación básica, sino por ciertas dificultades y por los refinamientos y complicaciones que se necesita para solucionarlas. Antes de tratarlos voy a introducir, como un refinamiento de mi propia explicación, la noción de un campo causal. ${ }^{14}$

progresiva localización de una causa. Una condición que es mínimamente suficiente en relación con un grado de análisis de los factores puede no serlo en relación con otro grado de análisis.

${ }^{13}$ Esta sección es algo así como un aparte: el argumento principal es retomado en $\S 3$.

${ }^{14}$ Esta noción de un campo causal fue introducida por John Anderson. La utilizó, e.g., en "The Problem of Causality", publicado por primera vez en el Australasian Journal of Phsychology and Philosophy, vol. 16 (1938), y reimpreso en Studies in Empirical Philosophy (Sydney, 1962), pp. 126-136, para solucionar ciertas dificultades y paradojas en la explicación que da Mill de la 
Esta noción puede explicarse del modo más sencillo si abandonamos, por un momento, los enunciados causales singulares y consideramos enunciados causales generales. La pregunta “¿qué causa la gripe?” es incompleta y está parcialmente indeterminada. Puede querer decir “¿Qué causa la gripe en los seres humanos en general?”. Si es así, la causa (completa) que está siendo buscada es una diferencia que va a distinguir casos en los que los seres humanos contraen gripe de casos en los que no lo hacen; el campo causal es entonces la región que ha se ser dividida de ese modo, seres humanos en general. Pero la pregunta puede querer decir, "Dado que están presentes virus de gripe, ¿qué hace que alguna gente contraiga la enfermedad mientras que otra gente no lo hace?" Aquí el campo causal es seres humanos en condiciones en las que están presentes virus de gripe. En todos los casos de este tipo, se requiere que la causa diferencie, al interior de una región más amplia en la que el efecto a veces ocurre y a veces no, la subregión en la que ocurre: esta región más amplia es el campo causal. Esta noción puede ahora ser aplicada a preguntas y enunciados causales singulares. "¿Qué causó el cáncer de piel de este hombre?”15 puede querer decir “¿Por qué este hombre desarrolló cáncer de piel ahora cuando no lo había desarrollado antes?" Aquí el campo causal es la carrera de este hombre: es al interior de ésta que estamos buscando una diferencia entre el momento en que se desarrolló el cáncer de piel y los momentos en los que no. Pero la misma pregunta puede querer decir “¿Por qué este hombre desarrolló cáncer de piel, mientras que otros hombres que también estuvieron expuestos a radiación no lo hicieron?” Aquí el campo causal es la clase de hombres expuestos a radiación. Y lo que es la causa en relación con un campo puede no ser la causa en relación con otro. La exposición a una cierta dosis de radiación puede ser la causa en relación con el primer campo: no puede ser la causa en relación con el segundo campo dado que es parte de la descripción de ese campo, y estando presente a lo largo y a lo ancho de todo ese campo no puede diferenciar una región de él de otra. En

causalidad. También he utilizado esta noción para tratar problemas de la responsabilidad legal y moral, en "Responsibility and Language", Australasian Journal of Philosophy, vol. 33 (1955), pp. 143-159.

${ }^{15}$ Estos ejemplos son tomados de Scriven, op. cit., pp. 409-410. Scriven los discute en relación con lo que llama una "clase de contraste", la clase de casos donde el efecto no ocurrió y con la que el caso en que sí ocurrió se contrasta. Lo que voy a llamar el campo causal es la suma lógica del caso (o casos) en que se dice que el efecto es causado y de lo que Scriven llama la clase de contraste. 
relación con este segundo campo, la causa puede ser, en los términos de Scriven, "Algún factor constitutivo aún no identificado".

En nuestro primer ejemplo de la casa que se incendió, la historia de esta casa es el campo en relación con el cual los expertos estaban buscando la causa del incendio: su pregunta era “¿Por qué esta casa se prendió fuego en esta ocasión, y no en otras?” Sin embargo, puede haber aún alguna indeterminación en esta elección de un campo causal. ¿Esta casa, considerada como el campo causal, incluye todas sus características, o todas sus características relativamente permanentes, o sólo algunas de éstas? Si tomamos a todas sus características, o incluso todas sus características relativamente permanentes, como constituyendo el campo, entonces algunas de las cosas que hemos tratado como condiciones - por ejemplo, la presencia de material inflamable cerca del lugar en el que ocurrió el cortocircuito - deberían ser consideradas como partes del campo, y no podríamos entonces tomarlas también como condiciones que, en relación con este campo, en tanto adiciones o intrusiones respecto de él, son necesarias o suficientes para alguna otra cosa. Debemos por lo tanto tomar a la casa, en la medida en que constituye el campo causal, como determinada sólo de una manera bastante general, sólo por algunas de sus características relativamente permanentes, y estaremos libres para tratar sus otras características como condiciones que no constituyen el campo, y no son partes de él, pero que pueden ocurrir dentro de él o ser agregadas a él. Es en general una cuestión arbitraria si una característica particular es considerada como una condición (esto es, como un posible factor causal) o como parte del campo, pero no puede ser tratada de las dos maneras a la vez. Si hemos de decir que algo le ocurrió a esta casa a causa de, o parcialmente a causa de, una cierta característica, estamos implicando que habría seguido siendo esta casa, la casa respecto de la cual estamos buscando la causa de esta ocurrencia, aún si no hubiera tenido esta característica particular.

Propongo ahora modificar la explicación dada más arriba de las afirmaciones usualmente hechas mediante enunciados causales singulares. Un enunciado de una forma tal como " $A$ causó $F$ " es normalmente elíptica, y debe ser expandida a " $A$ causó $F$ en relación con el campo C'. Y entonces, en lugar de la afirmación expresada en (i) más arriba, requerimos esto: 
(ia) $A$ es al menos una condición INIS de $F$ en el campo $C$ - esto es, hay una condición que, dada la presencia de las propiedades, cualquiera que éstas sean, que caracterizan a $C$ en su totalidad, es necesaria y suficiente para $F$, y que es de una de estas formas: $(A X$ o $Y),(A \circ Y), A X, A$.

Al analizar nuestros enunciados causales ordinarios, debemos admitir que el campo es a menudo presupuesto o sólo vagamente indicado, en lugar de ser especificado de manera precisa. Sin embargo, el campo en relación con el cual buscamos una causa de este efecto, o estamos diciendo que tal y cual cosa es una causa, puede estar suficientemente definido como para posibilitarnos decir que ciertos hechos o posibilidades son irrelevantes para el problema causal particular bajo consideración, porque constituirían un desplazamiento del campo pretendido a uno distinto. Así, si estamos buscando la causa, o causas, de la gripe, queriendo significar su(s) causa(s) en relación con el campo seres humanos, podemos rechazar, como no directamente relevante, evidencia que muestra que alguna causa propuesta no produce gripe en ratas. Si estamos buscando la causa del incendio en esta casa, podemos de manera semejante rechazar como irrelevante el hecho de que una causa propuesta no habría producido un incendio si la casa hubiera sido radicalmente diferente, o si hubiera estado en un contexto radicalmente diferente.

Esta modificación nos permite tratar la dificultad bien conocida de que es imposible encontrar una condición genuinamente suficiente, una que sea "por sí misma, adecuada para asegurar el efecto", ${ }^{16}$ sin incluir en la causa la totalidad del contexto, la totalidad del estado previo del universo (excluyendo de este modo toda probabilidad de repetición). Puede ser difícil encontrar siquiera una condición compleja que sea absolutamente suficiente para este fuego porque deberíamos incluir, como uno de los términos negativos de la conjunción, un ítem como que la tierra no es destruida por una explosión nuclear justo después de la ocurrencia de la condición INIS sugerida; pero es fácil y razonable decir

\footnotetext{
${ }^{16} \mathrm{Cf}$. Bertrand Russell, "On the Notion of Cause", Mysticism and Logic (Londres, 1917), p. 187. Cf. también la primera dificultad de Scriven, op. cit., p. 409: "En primer lugar, virtualmente no hay ninguna condición suficiente conocida, hablando literalmente, dado que la interferencia humana o accidental es posible de modo casi ilimitado, y difícil de excluir por una restricción específica sin incurrir en tautología". La introducción del campo causal también cubre automáticamente la tercera dificultad de Scriven y su tercer refinamiento, el de la clase de contraste y la relatividad de enunciados causales a contextos.
} 
simplemente que una explosión semejante nos llevaría, en más de un sentido, fuera del campo en el que estamos considerando este efecto. Es decir, puede no ser tan difícil encontrar una condición que sea suficiente en relación con el campo pretendido. Sin duda, esto quiere decir que los enunciados causales pueden ser vagos, en la medida en que la especificación del campo es vaga, pero esto no es un obstáculo serio para verificarlos o usarlos, ya sea en la ciencia o en contextos cotidianos. ${ }^{17}$

Es una característica vital de la explicación que estoy sugiriendo que podamos decir que $A$ causó $F$, en el sentido descrito, sin ser capaces de especificar de manera exacta los términos representados por ' $X$ ' e ' $Y$ ' en nuestra fórmula. Al decir que $A$ es al menos una condición INIS para $F$ en $C$, no se está diciendo qué otros factores, junto a $A$, estaban a la vez presentes y eran no redundantes, y no se está diciendo qué otra condiciones suficientes mínimas puede haber para $F$ en $C$. Ni siquiera se está afirmando que uno es capaz de decir cuáles son. Esto no es de ningún modo una dificultad: se trata de un hecho acerca de nuestros enunciados causales ordinarios que puede reconocerse con facilidad y que esta explicación refleja de modo explícito y correcto. ${ }^{18}$ Mostraremos (en $\S 5$ más abajo) que este carácter elíptico o indeterminado de nuestros enunciados causales está estrechamente conectado con algunos de nuestros modos característicos de descubrir y confirmar relaciones causales: es precisamente para enunciados que son así "con lagunas" o indeterminados que podemos obtener evidencia bastante directa a partir de rangos de

\footnotetext{
${ }^{17}$ J. R. Lucas, "Causation”, Analytical Philosophy, ed. R. J. Butler (Oxford, 1962), pp. 57-59 resuelve este tipo de dificultad apelando informalmente a algo que equivale a esta noción de un campo causal: “... estas circunstancias [cataclismos cósmicos, etc.] ... destruyen toda la situación causal en la que habíamos estado esperando que apareciera $Z$... no se supone que las predicciones resulten verdaderas cuando ocurren accidentes completamente imprevistos"

${ }^{18}$ Esto está relacionado con la segunda dificultad de Scriven, op. cit., p. 409: "sigue estando el problema de decir cuáles son los otros factores que, con la causa, constituyen la condición suficiente. Si pueden ser enunciados, la explicación causal es entonces simplemente un caso especial de subsunción bajo una ley. Si no pueden [ser enunciados], el análisis es con seguridad mitológico". Scriven responde correctamente que "una combinación de la tesis del macrodeterminismo ... y observación-más-teoría con frecuencia nos da la mejor de las razones para decir que un cierto factor se combina con un subconjunto desconocido de las condiciones presentes para dar lugar a una condición suficiente para un efecto particular". Da un ejemplo estadístico de una evidencia semejante, pero la totalidad de mi explicación de clases típicas de evidencia para relaciones causales en $\S \S 5$ y 7 más abajo es una defensa ampliada de una respuesta de esta clase.
} 
observación más bien modestos. Según este análisis, los enunciados causales contienen de manera implícita cuantificaciones existenciales; uno puede aseverar un enunciado existencialmente cuantificado sin aseverar ninguna instanciación de él, y uno puede también tener buenas razones para aseverar un enunciado existencialmente cuantificado sin tener la información necesaria para corroborar alguna instanciación precisa de él. Puedo saber que hay alguien en la puerta aún si no pudiera responder la pregunta “¿Quién es?”

Marc-Wogau está particularmente preocupado por casos donde "hay dos eventos, cada uno de los cuales es, con independencia del otro, una condición suficiente para otro evento". Es decir, hay dos condiciones suficientes mínimas, las dos de las cuales de hecho ocurren. Por ejemplo, un rayo cae sobre un granero en el que se almacena paja, y un vagabundo arroja una colilla de cigarrillo encendida a la paja en el mismo lugar al mismo tiempo. De manera semejante, para un evento histórico puede haber más que una "causa", y cada una de ellas puede, por sí misma, ser suficiente. ${ }^{19}$ De manera similar, Scriven considera un caso en el que

... hay condiciones (quizás una excitación inusual además de inadecuaciones constitutivas) presentes a las 4:00 P. M. que garantizan un infarto a las 4:55 P. M. y la muerte consecuente a las 5:00 P. M.; pero un ataque cardíaco completamente independiente a las 4:50 P. M. puede seguir siendo llamado la causa de la muerte, la que, según resulta, no ocurre a las 5:00 P.M. ${ }^{20}$

Antes de que intentemos resolver estas dificultades consideremos otro de los problemas de Marc-Wogau: Pérez y García cometen un crimen, pero si no lo hubieran cometido el jefe de la organización criminal habría enviado a otros miembros para realizarlo en su lugar, de manera que se habría cometido de todos modos. ${ }^{21}$ Ahora bien, en este caso, si ' $A$ ' se refiere a las acciones de Pérez y García, lo que tenemos es que $A X$ es

\footnotetext{
${ }^{19}$ Op. cit., pp. 228-233.

${ }^{20} \mathrm{Op}$. cit., pp. 410-411: esta es la cuarta dificultad y el cuarto refinamiento.

${ }^{21} \mathrm{Op}$. cit., p. 232: el ejemplo es tomado de P. Gardiner, The Nature of Historical Explanation (Oxford, 1952), p. 101.
} 
una condición suficiente mínima del resultado (el crimen), pero $\neg A Z$ es otra, y tanto $X$ como $Z$ están presentes. $A$ se combina con un conjunto de las condiciones constantes para producir el resultado por una ruta: pero la ausencia de $A$ se habría combinado con otro conjunto de las condiciones constantes para producir el mismo resultado por otra ruta. En este caso, podemos decir que $A$ fue una condición necesaria post factum. Esta muestra satisface los requisitos del análisis dado por Marc-Wogau, y los del mío propio, del enunciado de que $A$ causó este resultado; y esto concuerda con lo que normalmente diríamos en un caso semejante. (Podríamos por cierto agregar que también había una causa más profunda - la existencia de la organización criminal, quizás - pero esto no importa: nuestros análisis formales no aseguran que un resultado particular tendrá una única causa, ni nuestro modo corriente de hablar sobre las causas lo requiere). Es cierto que en este caso no podemos decir lo que normalmente serviría como un reemplazo informal de la explicación formal, a saber, que la causa, aquí $A$, era necesaria (así como suficiente) en las circunstancias: pues $\neg A$ también habría resultado suficiente. Ni siquiera podemos decir que $A$ fue no redundante. Pero esto muestra meramente que un análisis formal puede ser superior a sus contrapartes menos formales.

Ahora bien, en el ejemplo de Scriven, podríamos suponer que el ataque cardíaco impidió que ocurriera el infarto. Si esto es así, entonces el ataque cardíaco es una condición necesaria post factum: es un momento en la única condición suficiente mínima que estaba completamente presente, ya que el ataque cardíaco desplazó algún factor que era una parte necesaria de la condición suficiente mínima que tiene a la excitación como uno de sus momentos. Esto es estrictamente paralelo al caso de Pérez y García. De nuevo, es extraño decir que el ataque cardíaco fue en alguna medida necesario, dado que la ausencia del ataque cardíaco habría sido igualmente suficiente: esta ausencia habría sido un momento en esa otra condición suficiente mínima, uno de cuyos otros momentos fue la excitación. Sin embargo, el ataque cardíaco fue necesario post factum, y la excitación no. Scriven traza la distinción, de modo correcto, en términos de la continuidad y la discontinuidad de las cadenas causales: "el ataque cardíaco fue, y la excitación no fue, la causa de la muerte porque la 'cadena causal' entre la segunda y la muerte fue interrumpida, mientras que la de la primera "llegó a completarse"”. Pero vale la pena notar que un quiebre en la cadena 
causal corresponde a la no satisfacción de los requisitos lógicos para ser un momento en una condición suficiente mínima que es también necesaria post factum.

Alternativamente, si el ataque cardíaco no impidió el infarto, entonces tenemos un caso paralelo al de la paja en el granero, o al del hombre que es disparado por un pelotón de fusilamiento, y dos balas atraviesan su corazón simultáneamente. En tales casos, los requisitos de mi análisis, o los del de Marc-Wogau, o los del de Scriven, no son satisfechos: cada causa propuesta es redundante y ni siquiera es necesaria post factum, si bien la disyunción de ellas es necesaria post factum y no redundante. Pero esto concuerda muy bien con el hecho de que ordinariamente dudaríamos sobre si decir, de cada una de las balas, que ella causó la muerte del hombre, o del rayo o la colilla de cigarrillo que causaron el incendio, o de la excitación o el ataque cardíaco que fue la causa de la muerte. Como dice Marc-Wogau, “en una situación tal como ésta tampoco estamos seguros de cómo usar la palabra "causa"'. Nuestro concepto ordinario de causa no trata claramente con casos de este tipo, y somos libres para decidir si agregar o no a nuestro uso ordinario, y a las varias descripciones más o menos formales de él, reglas que nos permitan decir que donde están presentes más de una condición-al-menos-INIS y las condiciones que están en conjunción con ellas, cada una de ellas causó el resultado. ${ }^{22}$

La explicación desarrollada hasta aquí de los enunciados causales singulares ha sido expresada en términos de enunciados acerca de la necesidad y la suficiencia; por lo tanto está incompleta hasta que hayamos agregado una explicación de la necesidad y la suficiencia mismas. Esta cuestión es considerada en el $\S 4$ más abajo. Pero la explicación que estamos dando es independiente de cualquier análisis particular de la necesidad y la suficiencia. Cualquiera sea el análisis de éstas que finalmente adoptemos, lo vamos a usar para completar la explicación de en qué consiste ser una condición INIS, o ser al menos una condición INIS. Pero sea cual fuera la forma en que esta explicación sea completada, podemos retener el principio general de que al menos parte de lo que a menudo se hace mediante un enunciado causal singular es seleccionar, como la causa, algo de lo que se afirma que es al menos una condición INIS.

\footnotetext{
${ }^{22}$ La quinta dificultad de Scriven y el quinto refinamiento se ocupan de la dirección de la causación. Esto es considerado brevemente en el $\S 8$ más abajo.
} 


\section{Enunciados causales generales.}

Muchos enunciados causales generales deben ser entendidos de una manera correspondiente. Supongamos, por ejemplo, que un economista dice que la restricción del crédito causa (o produce) desempleo. De nuevo, sin duda estará hablando con referencia a algún campo causal; éste ahora no es un objeto individual, sino una clase, presumiblemente, la de las economías de un cierto tipo general; quizás su especificación incluirá la característica de que cada economía del tipo en cuestión contiene un importante sector de empresas privadas con empleados asalariados libres. El resultado, el desempleo, es algo que a veces ocurre y a veces no ocurre al interior de este campo, y lo mismo es verdadero de la supuesta causa, la restricción del crédito. Pero el economista no está diciendo que (siquiera en relación con este campo) la restricción del crédito es o bien necesaria o bien suficiente para el desempleo, y mucho menos que es tanto necesaria como suficiente. Puede muy bien haber otras circunstancias que deben estar presentes junto con la restricción del crédito, en una economía del tipo al que nos referimos, si ha de resultar el desempleo; estas otras circunstancias sin duda incluirán varias de tipo negativo, la ausencia de varios factores causales que contrarrestarían y que, si estuvieran presentes, impedirían este resultado. También, el economista probablemente estará preparado a admitir que en una economía de este tipo el desempleo podría ser producido por otras combinaciones de circunstancias en las cuales la restricción del crédito no cumple ningún papel. De modo que, una vez más, la afirmación que está haciendo es meramente que la restricción del crédito es, en economías de este tipo, una parte no redundante de una condición suficiente para el desempleo: esto es, que es una condición INIS. El economista probablemente está suponiendo que hay alguna condición, sin dudas una condición compleja, que es a la vez necesaria y suficiente para el desempleo en este campo. Habiéndose supuesto esto, lo que está afirmando es que, para algún $X$ y para algún $Y$, ( $A X$ o $Y$ ) es una condición necesaria y suficiente para $F$ en $C$, pero ni $A$ ni $X$ son suficientes por sí solas, donde ' $A$ ' refiere a la restricción del crédito, ' $F$ ' al desempleo, y ' $C$ ' al campo, economías de tal y cual tipo. En una teoría económica desarrollada el campo puede ser especificado con bastante exactitud, y también pueden serlo las combinaciones relevantes 
de factores representadas aquí por ' $X$ ' e ' $Y$ '. (En verdad, la teoría puede ir más allá de enunciados en términos de necesidad y suficiencia hacia otros de dependencia funcional, pero esta es una complicación que estoy dejando de lado por el momento). En una formulación preliminar o simplificada, por otra parte, las combinaciones de factores pueden ser, o bien indicadas sólo de un modo tosco, o bien ser dejadas completamente indeterminadas. En un extremo tenemos el enunciado de que $(A X$ o $Y)$ es una condición necesaria y suficiente, donde se asignan a ' $X$ ' e ' $Y$ ' significados definidos; en el otro extremo tenemos el enunciado meramente existencialmente cuantificado según el cual esto se da para algún par $X$ e $Y$. Nuestro conocimiento en tales casos ordinariamente cae en algún lugar entre estos dos extremos. Podemos usar la misma convención que antes, permitiendo deliberadamente que sea ambigua entre estas distintas interpretaciones, y decir que en cualquiera de estos casos, donde $A$ es una condición INIS de $F$ en $C,(A \ldots$ o $\ldots)$ es una condición necesaria y suficiente de $F$ en $C$.

Una gran cantidad de nuestro conocimiento causal ordinario es de esta forma. Sabemos que comer dulces causa deterioro dental. Aquí el campo es los seres humanos algunos de cuyos dientes son propios. No sabemos, de hecho no es verdad, que el que cualquiera de estas personas coma dulces es una condición suficiente para el deterioro dental: alguna gente tiene dientes especialmente resistentes, y hay probablemente medidas que, si se las toma a la vez que se comen dulces, protegerían a los dientes del deterioro. Todo lo que sabemos es que comer dulces, combinado con un conjunto de factores positivos y negativos que sólo podemos especificar, si es que podemos hacerlo, de un modo tosco e incompleto, constituye una condición suficiente mínima del deterioro dental - pero no una condición necesaria, pues hay otras combinaciones de factores, que no incluyen comer dulces, que también deteriorarían los dientes, pero que sólo podemos especificar, si es que podemos hacerlo, de un modo tosco e incompleto. Esto es, si ' $A$ ' ahora representa comer dulces, ' $F$ ' el deterioro dental y ' $C$ ' la clase de seres humanos algunos de cuyos dientes son propios, podemos decir que, para algún $X$ e $Y,(A X \circ Y)$ es necesario y suficiente para $F$ en $C$, y podríamos ser capaces de ir más allá de este enunciado meramente existencialmente cuantificado hasta al menos una especificación parcial de los $X$ e $Y$ en cuestión. Esto es, podemos decir que $(A \ldots$ o ...) es una condición necesaria y suficiente, pero que $A$ misma es solo una condición INIS. Y lo mismo vale para muchos enunciados 
causales generales de la forma “ $A$ causa (o produce) $F$ ”. Es en este sentido que la aplicación de una diferencia de potencial a los extremos de un cable de cobre produce una corriente eléctrica en el cable; que una elevación en la temperatura de una pieza de metal la hace dilatarse; que la humedad oxida el acero; que la exposición a varios tipos de radiación causa cáncer, etc.

Sin embargo, es verdad que no todos los enunciados causales generales ordinarios son de este tipo. Algunos de ellos son enunciados implícitos de dependencia funcional. La dependencia funcional es una relación más complicada respecto de la cual la necesidad y la suficiencia pueden ser consideradas como casos especiales. (La tratamos brevemente en el $\S 7$ más abajo). Aquí también lo que normalmente identificamos como causando algún resultado es sólo uno de un número de factores que de manera conjunta afectan el resultado. Otra vez, algunos enunciados causales seleccionan algo que es no sólo una condición INIS, sino también una condición necesaria. Así, podemos decir que el virus de la fiebre amarilla es la causa de la fiebre amarilla. (Este enunciado no es, como podría parecer, tautológico, ya que el virus de la fiebre amarilla y la enfermedad misma pueden ser especificados de manera independiente). En el campo en cuestión - los seres humanos - la inyección de este virus no es por sí misma una condición suficiente de la enfermedad, ya que personas que se recuperaron alguna vez de la fiebre amarilla son en lo sucesivo inmunes a ella, y otras personas pueden ser inmunizadas contra ella. La inyección del virus, combinada con la ausencia de inmunidad (natural o artificial), y quizás combinada con algunos otros factores, constituye una condición suficiente de la enfermedad. Además de esto, la inyección del virus es una condición necesaria de la enfermedad. Si hay más de una condición suficiente compleja de la fiebre amarilla, la inyección del virus en la corriente sanguínea del paciente (ya sea por un mosquito o de algún otro modo) es un factor que está incluido en toda condición suficiente semejante. $\mathrm{Si}$ ' $A$ ' refiere a este factor, la condición necesaria y suficiente tiene la forma ( $A \ldots$ o $A \ldots$ etc.), donde $A$ ocurre en cada disyunto. A veces notamos la diferencia entre este caso y el caso estándar usando la frase "la causa". Podemos decir no meramente que este virus causa la fiebre amarilla, sino que es la causa de la fiebre amarilla; pero sólo diríamos que comer dulces causa el deterioro dental, no que es la causa del deterioro dental. Pero acerca de un caso individual podríamos decir que comer dulces fue la causa del deterioro de los dientes de esta persona, queriendo decir (como en $\S 1$ más 
arriba) que la única condición suficiente presente aquí fue aquella que incluía comer dulces como una parte no redundante. Sin embargo, no habrá en general ningún ítem que tenga un derecho exclusivo a ser considerado como la causa siquiera de un evento individual, aún luego de que el campo causal haya sido determinado. Cada uno de los momentos en la condición suficiente mínima, o en cada condición suficiente mínima, que estaba presente puede ser igualmente considerado como la causa. Pueden ser distinguidas como causas que predisponen, causas que ocasionan, etc., pero es bastante arbitrario seleccionar como "principales" o "secundarios" diferentes momentos que son igualmente ítems no redundantes en una condición suficiente mínima, o que son momentos en dos condiciones suficientes mínimas cada una de las cuales hace a la otra redundante. ${ }^{23}$

\section{Necesidad y suficiencia.}

Una explicación posible de los enunciados generales de las formas " $S$ es una condición necesaria de $T$ " y " $S$ es una condición suficiente de $T$ " - donde ' $S$ ' y ' $T$ ' son términos generales - es que son equivalentes a proposiciones universales simples. Esto es, el primero es equivalente a "Todos $\operatorname{los} T$ son $S$ " y el segundo a "Todos $\operatorname{los} S$ son $T$ ". De manera similar, " $S$ es necesario para $T$ en el campo $C$ " sería equivalente a "Todos los $C T$ son $S$ ", y " $S$ es suficiente para $T$ en el campo $C$ " a "Todos los $C S$ son $T$ ". Si una explicación de este tipo es adecuada es, por supuesto, una cuestión disputada; pero no es disputado que estos enunciados acerca de condiciones necesarias y suficientes al menos implican los universales correspondientes. Trabajaré bajo la suposición de que esta explicación es adecuada, que los enunciados generales de necesidad y suficiencia son equivalentes a universales: valdrá la pena ver hasta dónde nos llevará esta explicación, hasta dónde somos capaces de comprender, en sus términos, cómo usamos, corroboramos y criticamos estos enunciados de necesidad y suficiencia.

Una explicación directamente análoga de los enunciados singulares correspondientes no es satisfactoria. Así no será suficiente decir que "Un cortocircuito aquí fue una condición necesaria de un incendio en esta casa" es equivalente a "Todos los casos

\footnotetext{
${ }^{23} \mathrm{Cf}$. las observaciones finales de Marc-Wogau, op. cit., pp. 232-233.
} 
en que esta casa se incendia son casos en que un cortocircuito ocurre aquí", porque el último es automáticamente verdadero si esta casa se ha incendiado sólo una vez y un cortocircuito ha ocurrido en esa ocasión, pero esto no es suficiente para establecer el enunciado de que el cortocircuito era una condición necesaria del incendio; y habría una objeción exactamente paralela a un enunciado similar acerca de una condición suficiente.

Es mucho más plausible relacionar los enunciados singulares acerca de la necesidad y la suficiencia con ciertos tipos de condicionales no materiales. Así, "un cortocircuito aquí era una condición necesaria de un incendio en esta casa" está relacionado estrechamente con el condicional contrafáctico "Si no hubiera ocurrido un cortocircuito aquí esta casa no se habría incendiado", y "Un cortocircuito aquí fue una condición suficiente de un incendio en esta casa" está relacionado estrechamente con lo que Goodman ha denominado el condicional fáctico "Dado que un cortocircuito ocurrió aquí, esta casa se incendió”.

Sin embargo, aún debería darse una explicación ulterior de estos condicionales no materiales mismos. He argumentado en otro lugar ${ }^{24}$ que el mejor modo de considerarlos es como argumentos condensados o telescópicos, pero que los enunciados usados como premisas en estos argumentos no son otra cosa que universales fácticos simples. Usar el contrafáctico citado más arriba es, en efecto, recorrer un argumento incompleto: "Supongamos que un cortocircuito no ocurrió aquí, entonces la casa no se incendió". Usar el condicional fáctico es, en efecto, recorrer un argumento incompleto similar, "Un cortocircuito ocurrió aquí; por lo tanto, la casa se incendió”. En cada caso el argumento podría en principio ser completado mediante la inserción de otras premisas que, junto con la premisa expresada, podrían implicar la conclusión expresada. Puede decirse que tales premisas adicionales fundamentan el condicional no material. Es un punto importante que alguien puede usar un condicional no material sin completar o sin ser capaz de completar el argumento, sin estar preparado para aseverar explícitamente las premisas que lo fundamentan y, de manera similar, que podemos entender un condicional semejante sin conocer cómo el argumento sería o podría ser completado. Pero decir que un cortocircuito aquí era una condición necesaria de un incendio en esta casa es decir que hay algún

\footnotetext{
24“Counterfactuals and Causal Laws", Analytical Philosophy, ed. R. J. Butler (Oxford, 1962), pp. 66-80.
} 
conjunto de proposiciones verdaderas que fundamentarían el contrafáctico expresado más arriba, y decir que fue una condición suficiente es decir que hay algún conjunto de proposiciones verdaderas que fundamentarían el condicional fáctico expresado más arriba. Si se concede esto, entonces el relacionar enunciados singulares acerca de la necesidad y la suficiencia con condicionales no materiales conduce nuevamente a la idea de que refieren de manera indirecta a ciertas proposiciones universales simples. Así, si dijéramos que un cortocircuito aquí era una condición necesaria para un incendio en esta casa, estaríamos diciendo que hay proposiciones universales verdaderas a partir de las cuales, junto con enunciados verdaderos acerca de las características de esta casa, y junto con la suposición de que un cortocircuito no ocurrió aquí, se seguiría que la casa no se incendió. A partir de aquí podemos inferir la proposición universal que es el candidato más obvio, pero insatisfactorio, para el análisis de este enunciado de necesidad, "Todos los casos en que esta casa se incendia son casos en que un cortocircuito ocurre aquí" o, en nuestros símbolos, "Todos los $C F$ son $A$ ". Podemos usar esto para representar aproximadamente el enunciado de necesidad, bajo la suposición de que ha de ser una consecuencia de algún conjunto de proposiciones universales más abarcadoras, y que no ha de ser automáticamente verdadero meramente porque sólo hay este único caso de un $C F$, de que esta casa se incendie. ${ }^{25}$ Un enunciado de que $A$ era una condición suficiente puede ser representado, de manera similar, mediante "Todos los $C A$ son $F$ ". Correspondientemente, si todo lo que queremos decir es que $(A \ldots$ o $\ldots)$ era necesario y suficiente para $F$ en $C$, esto será representado aproximadamente mediante el par de universales "Todos los $C F$ son $\left(A \ldots\right.$ o ...), y todos $\operatorname{los} C\left(A \ldots\right.$ o ...) son $F^{\prime}$, y más precisamente mediante el enunciado de que hay algún conjunto de proposiciones universales más abarcadoras a partir de las cuales, junto con enunciados verdaderos acerca de las características de $C$, se sigue este par de universales. Este es, por lo tanto, el análisis más completo de la afirmación de que,

\footnotetext{
${ }^{25}$ Esta restricción puede compararse con una que Nagel impone sobre las leyes de la naturaleza: "La verdad vacua de un universal irrestricto no es suficiente para contarlo como una ley; cuenta como una ley sólo si hay un conjunto de otras leyes presupuestas a partir de las cuales el universal es derivable lógicamente" (The Structure of Science [Nueva York: 1961], p. 60. Habría sido mejor si hubiera agregado "o si hay algún otro modo en el que es sostenida (en última instancia) por la evidencia empírica". Cf. mis observaciones en "Counterfactuals and Causal Laws", op. cit., pp. 72$74,78-80$.
} 
en un caso particular, $A$ es una condición INIS de $F$ en $C$, y por lo tanto del enunciado singular de que $A$ causó $F$. (El enunciado de que $A$ es al menos una condición INIS incluye otras alternativas, que corresponden a los casos donde la condición necesaria y suficiente es $(A \circ \ldots), A \ldots$, о $A)$.

Volvamos ahora a los enunciados generales de necesidad y suficiencia y tomemos a $C$ como una clase, no como un individuo. Según la posición que estoy adoptando, al menos de manera provisoria, el enunciado de que $Z$ es una condición necesaria y suficiente para $F$ en $C$ es equivalente a "Todos $\operatorname{los} C F$ son $Z$ y todos $\operatorname{los} C Z$ son $F$ ". De manera similar, si no podemos especificar completamente una condición necesaria y suficiente para $F$ en $C$, pero sólo podemos decir que la fórmula " $(A \ldots$ o ...)" representa una condición semejante, ésta es equivalente al par de universales incompletos "Todos los $C F$ son $(A \ldots$ o ...) y todos $\operatorname{los} C\left(A \ldots\right.$ o ...) son $F^{\prime \prime}$. Al decir que nuestros enunciados causales generales a menudo no hacen más que especificar una condición INIS, estoy por lo tanto diciendo que mucho de nuestro conocimiento causal ordinario es conocimiento de tales pares de universales incompletos, de lo que podemos llamar leyes causales elípticas o con lagunas.

\section{Evidencia para conexiones causales.}

Si suponemos que el enunciado causal general de que $A$ causa $F$, o que el enunciado causal singular de que $A$ causó $F$, a menudo realizan las afirmaciones desplegadas en los $\S \S 1,2,3$ y 4, incluyendo la afirmación de que $A$ es al menos una condición INIS de $F$, entonces podemos dar una explicación de una combinación de razonamiento y observación que constituye evidencia para estos enunciados causales.

Esta explicación está basada en lo que von Wright llama un caso complejo ${ }^{26}$ del Método de la Diferencia. Como cualquier otro método de inducción eliminativa, éste puede

\footnotetext{
${ }^{26}$ A Treatise on Induction and Probability (Nueva York, 1951), pp. 90 ss. La explicación que estoy dando aquí del Método de la Diferencia, y la que daría de los métodos eliminativos de la inducción en general, difiere, sin embargo, en diversos aspectos de la de von Wright. Un artículo, "Eliminative Methods of Induction", que presenta mi explicación, va a aparecer en la Encyclopedia of Philosophy, editada por Paul Edwards, y que será publicada por la Free Press de Glencoe, CollierMacmillan.
} 
ser formulado en términos de una suposición, una observación y una conclusión que se sigue mediante un argumento deductivamente válido a partir de la suposición y la observación tomadas en conjunto. Para obtener una conclusión positiva mediante un proceso de eliminación, debemos suponer que el resultado (el fenómeno una de cuyas causas vamos a descubrir) tiene alguna causa en el sentido de que hay alguna condición cuya ocurrencia es tanto necesaria como suficiente para la ocurrencia (regularmente, poco tiempo después) del resultado. También, si es que hemos de ir a algún lado mediante la eliminación, debemos suponer que el rango de factores causales posiblemente relevantes, esto es, de los ítems que podrían de alguna manera constituir esta condición necesaria y suficiente, está restringido de alguna manera. Por otra parte, aún si hubiéramos especificado algún conjunto semejante de factores posiblemente relevantes, sería en la mayor parte de los casos bastante implausible suponer que la supuesta condición necesaria y suficiente es idéntica a solo uno de estos factores tomado por sí mismo, y afortunadamente no tenemos ninguna necesidad de hacer esto. Si representamos cada factor posiblemente relevante como un único término, la suposición natural a hacer es simplemente que la supuesta condición necesaria y suficiente estará representada por una fórmula que está de alguna manera construída a partir de alguna selección de estos términos únicos, mediante negación, conjunción y disyunción. Sin embargo, cualquier fórmula así construida es equivalente a alguna fórmula de forma disyuntiva normal - esto es, una en la que la negación, si ocurre, se aplica sólo a términos singulares y [en que] la conjunción, si ocurre, [se aplica] sólo a términos singulares y/o negaciones de términos singulares. De modo que podemos suponer, sin pérdida de generalidad, que la fórmula de la supuesta condición necesaria y suficiente está en una forma disyuntiva normal, que es a lo sumo una disyunción de conjunciones en las que cada miembro de la conjunción es un término singular o su negación, esto es, una fórmula tal como “( $A B C$ o $G H$ o $J)$.” Resumiendo esto, la suposición que requerimos tendrá esta forma:

Para algún $Z, Z$ es una condición necesaria y suficiente para el fenómeno $F$ en el campo $C$, esto es, todos los $C F$ son $Z$ y todos los $C Z$ son $F$, y $Z$ es una condición representada mediante alguna fórmula en forma disyuntiva normal, cuyos constituyentes son todos tomados del rango de factores posiblemente relevantes $A, B, D, E$, $G$, etc. 
Junto con esta presuposición, necesitamos una observación que tiene la forma de la clásica observación de diferencia descrita por Mill. Podemos formularla como sigue:

Hay una instancia $I_{1}$ en la que $F$ ocurre y un caso negativo $N_{1}$ en el que $F$ no ocurre, tales que uno de los factores posiblemente relevantes (o su negación), digamos, $A$, está presente en $I_{1}$ y ausente de $N_{1}$, pero cada uno de los otros factores posiblemente relevantes está o bien presente tanto en $I_{1}$ como en $N_{1}$ o ausente tanto de $I_{1}$ como de $N_{1}$.

Podemos presentar un ejemplo de una observación semejante como sigue, usando 'a' y 'p' en lugar de "ausente" y "presente".

$\begin{array}{llllllll}F & & A & B & D & E & G & \\ I_{1} & p & p & p & a & a & p & \text { etc. } \\ & & & & & & \\ N_{1} & a & a & p & a & a & p\end{array}$

Dada la presuposición señalada más arriba, podemos razonar de la manera siguiente acerca de cualquier observación de este tipo:

Dado que $F$ está ausente de $N_{1}$, toda condición suficiente para $F$ está ausente de $N_{1}$, y por lo tanto todo disyunto en $Z$ está ausente en $N_{1}$. Todo disyunto en $Z$ que no contiene a $A$ está por lo tanto también ausente de $I_{1}$. Pero, dado que $F$ está presente en $I_{1}, \mathrm{y} Z$ es una condición necesaria para $F, Z$ está presente en $I_{1}$. Por lo tanto, al menos un disyunto en $Z$ está presente en $I_{1}$. Por lo tanto, al menos un disyunto en $Z$ contiene a $A$.

Lo que esto muestra es que $Z$, la condición supuestamente necesaria y suficiente para $F$ en $C$, es o bien $A$ misma, o una conjunción que contiene a $A$, o una disyunción que contiene como disyunto ya sea $A$ misma o una conjunción que contiene a $A$. Esto es, $Z$ tiene una de estas cuatro formas: $A ; A \ldots ;(A \circ \ldots) ;(A \ldots$ o ... $)$. Podemos resumir estas formas diciendo que $Z$ tiene la forma ( $A$--- o ---), donde los guiones indican que esas partes de la fórmula pueden estar o no llenas. Esto representa en breve el enunciado de que $A$ es al 
menos una condición INIS. Se sigue también que que si hay en la fórmula (desconocida) que representa la condición necesaria y suficiente completa algún disyunto que no contiene a $A$, ninguno de ellos estaba presente como un todo en $N_{1}$ (pero, por supuesto, algunos de sus términos componentes pueden haber estado presentes allí), y también que en al menos uno de los disyuntos que contiene a $A$ los términos, si es que hay alguno, que están conjuntados con $A$ representan factores (o negaciones de factores) que estaban presentes en $I_{1}$. Esto es todo lo que se sigue de esta sola observación. Pero, en general, otras observaciones mostrarán que los lugares con puntos tienen que estar llenos, y que $A$ sola no es ni necesaria ni suficiente para $F$ en $C$. Podemos entonces inferir que la condición necesaria y suficiente tiene de hecho la forma $(A \ldots$ o ... ) , y que $A$ misma sólo es una condición INIS.

Este análisis es hasta aquí meramente formal, y tenemos todavía que considerar si un método semejante puede ser, o es, usado de hecho, si una suposición del tipo requerido puede ser justificada y si una observación del tipo requerido puede alguna vez ser realizada. Incluso en este estadio, sin embargo, vale la pena notar que el Método de la Diferencia no requiere el tipo de presuposición completamente poco realista usada en lo que von Wright llama el caso simple - a saber, que la supuesta condición necesaria y suficiente es por sí misma algún factor simple - sino que la presuposición mucho menos restrictiva usada aquí seguirá proporcionando información aún cuando se la combine sólo con la clásica observación de diferencia. También vale la pena notar que la información así obtenida, si bien no llega a ser por mucho lo que von Wright llama una analogía absolutamente perfecta, esto es, la especificación completa de una condición necesaria y suficiente, es información de la forma exacta que está implícita en nuestras afirmaciones causales ordinarias, tanto singulares como generales. ${ }^{27}$

\footnotetext{
${ }^{27}$ Lo que se establece mediante el método presente puede ser comparado con las cuatro afirmaciones listadas en $\S 1$ más arriba, que $A$ es al menos una condición INIS, que $A$ estaba presente en la ocasión en cuestión, que los factores representados por ' $X$ ' - esto es, los otros momentos de al menos una condición suficiente mínima de la que $A$ es un momento - estaban presentes, y que todo disyunto en $Y$ que no contiene a $A$ - esto es, toda condición suficiente mínima que no contiene a $A$ - estaba ausente.
} 
Pero, ¿pueden hacerse observaciones del tipo requerido? Una respuesta preliminar es que el típico experimento controlado es un intento de aproximarse a una observación de este tipo. El caso experimental corresponde a nuestro $I_{1}$, el caso de control a nuestro $N_{1}, \mathrm{y}$ el experimentador intenta asegurar que no habrá ninguna diferencia posiblemente relevante entre estos dos casos con excepción de aquella cuyo efecto está intentando determinar, nuestro $A$. Cualquier resultado diferencial, presente en el caso experimental pero no en el caso de control, es lo que toma como este efecto, correspondiente a nuestro $F$.

La observación antes-y-después es una variedad particularmente importante de este tipo. Supóngase, por ejemplo, que tomamos un trozo de papel tornasol azul y lo sumergimos en un cierto líquido, y que se vuelve rojo. La situación antes de que se lo sumerja provee el caso negativo $N_{1}$; la situación después de que se lo sumerge provee la instancia $I_{1}$. Hasta donde podemos ver, ningún otro aspecto de la situación posiblemente relevante ha cambiado, de modo que $I_{1}$ y $N_{1}$ son semejantes respecto de todos los factores posiblemente relevantes con excepción de $A$, que el papel sea sumergido en un líquido de este tipo, pero el resultado $F$, que el papel se vuelva rojo, está presente en $I_{1}$ pero no en $N_{1}$. Podemos tomar esto de alguna de estas dos maneras. En primer lugar, podemos tomar el campo $C$ como consistiendo de trozos de papel de tornasol azul, y si suponemos que en este campo hay alguna condición suficiente y necesaria para $F$, formada de alguna manera a partir de alguna selección de los factores que estamos considerando como posiblemente relevantes, podemos concluir que ( $A$--- o --- ) es necesaria y suficiente para $F$ en $C$. Otras observaciones pueden mostrar que $A$ sola no es ni necesaria ni suficiente, y que por lo tanto la condición necesaria y suficiente es $(A \ldots$.... . . Así, podemos establecer la ley causal con lagunas "Todos $\operatorname{los} C F \operatorname{son}(A \ldots \mathrm{o} \ldots)$ y todos $\operatorname{los} C(A \ldots \mathrm{o} \ldots)$ son $F$ ”. Esto es equivalente a la aseveración de que en algunas circunstancias ser sumergido en un líquido de este tipo vuelve rojo al papel de tornasol azul. En segundo lugar, podemos considerar que el campo (que aquí llamaremos $C_{l}$ ) es este trozo particular de papel, y lo que el experimento establece entonces es el enunciado causal singular de que en esta ocasión particular la sumersión en este líquido volvió rojo a este trozo de papel. Esto es establecido de acuerdo con el análisis de los enunciados causales singulares completado en $\S 4$. Pues el experimento, junto con la presuposición, ha establecido los universales más amplios indicados mediante la ley causal con lagunas enunciada más arriba. Ha mostrado que para 
algún $X$ e $Y$ todos los $C F$ son $(A X$ o $Y)$ y todos los $C(A X$ o $Y)$ son $F$, y de esto, dado que $C_{1}$ es un $C$ (esto es, este trozo de papel es un trozo de papel de tornasol azul), se sigue que para algún $X$ e $Y$ todos $\operatorname{los} C_{l} F$ son $(A X$ o $Y)$ y todos los $C_{l}(A X$ o $Y)$ son $F$. También, ' $X$ ' representa circunstancias que estaban presentes en esta ocasión, e ' $Y$ ' circunstancias que no estaban presentes en $N_{1}$, la situación de "antes". Es decir, la observación, conjuntamente con la presuposición apropiada, implica que hay proposiciones verdaderas que sostienen los condicionales fácticos y contrafácticos, "Si, en las circunstancias, este papel no hubiera sido sumergido en este líquido, éste no se habría vuelto rojo, pero dado que que fue sumergido se volvió rojo"; pero no determina de modo completo cuáles son estas proposiciones, no llena los lugares vacíos en las leyes causales que sostienen a estos condicionales. La importancia de esto es que muestra cómo una observación puede revelar no meramente una secuencia sino una secuencia causal: lo que descubrimos no es meramente que el papel de tornasol fue sumergido y entonces se volvió rojo, sino que la sumersión hizo que se volviera rojo.

Vale la pena notar que a pesar del acento que tradicionalmente se pone, en las explicaciones del Método de la Diferencia, en el requisito de que debería haber solo un punto de diferencia entre $I_{1}$ y $N_{1}$, es muy poco en verdad lo que está en juego en ello. Pues supóngase que dos de nuestros factores posiblemente relevantes, digamos, $A$ y $B$, estuvieran ambos presentes en $I_{1}$ y ausentes en $N_{1}$, pero que cada uno de los otros factores posiblemente relevantes estaba o bien presente en ambos o ausente de ambos. Entonces, un razonamiento paralelo al dado más arriba mostrará que al menos uno de los disyuntos en $Z$ o bien contiene a $A$ o bien contiene a $B$ (y puede contener a ambos). Esto es, la observación nos sigue sirviendo para mostrar que el conjunto de factores $(A, B)$ contiene algo que es al menos una condición INIS de $F$ en $C$, ya sea que esta condición resulte ser sólo $A$, sólo $B$, la conjunción $A B$, o la disyunción $(A \circ B)$. Y consideraciones similares se aplican si hay más de dos puntos de diferencia entre $I_{1}$ y $N_{1}$. No importa cuántos haya, una observación de esta forma, en conjunción con nuestra suposición, muestra que una causa en nuestro sentido (una condición INIS en general) está en algún lugar dentro del conjunto de términos, positivos o negativos, respecto de los cuales $I_{1}$ difiere de $N_{1}$. (Nótese que ella no muestra que los otros términos, aquellos comunes tanto a $I_{1}$ como a $N_{1}$, son causalmente 
irrelevantes; nuestro razonamiento no excluye factores como irrelevantes, sino que localiza positivamente algunos de los factores relevantes al interior del cúmulo diferenciador).

Este hecho refuta la crítica que a veces se formula en contra de los métodos eliminativos de que presuponen y requieren un análisis satisfactorio definitivo de los factores causales en sus componentes simples, lo que de hecho nunca logramos. Por el contrario, cualquier distinción de factores, por más tosca que sea, nos permite comenzar a usar un método semejante. Podemos avanzar, y no hay duda de que los descubrimientos a menudo han avanzado, mediante lo que podemos denominar la localización progresiva de una causa. Usando el Método de la Diferencia de un modo muy tosco, podemos descubrir, en primer lugar, digamos, que la ingesta de vino causa embriaguez. Esto es, el cúmulo de factores que es resumido de un modo crudo en el único término "la ingesta de vino" contiene en algún lugar en su interior una condición INIS de la embriaguez; y podemos de manera subsiguiente continuar distinguiendo varios factores posiblemente relevantes al interior de este cúmulo, y localizar de modo más preciso una causa de la embriaguez mediante observaciones adicionales del mismo tipo. En un contexto en que este cúmulo es introducido o excluido como un todo, es correcto decir que la introducción de este cúmulo era no redundante o necesario post factum, y los experimentos pueden establecer esto, aún si, en un contexto diferente, en el que los distintos ítems en el cúmulo son introducidos o excluidos de manera separada, sería correcto decir que solo un ítem, el alcohol, era no redundante o necesario post factum, y esto podría ser establecido mediante una experimentación más exacta.

Un mérito de este análisis formal es que muestra en qué sentido un método de inducción eliminativa, tal como el Método de la Diferencia, descansa sobre un principio determinista o presupone la uniformidad de la naturaleza. De hecho, cada aplicación de este método requiere una suposición que en un respecto dice mucho menos que esto, y en otro un poco más. No se necesita ninguna suposición general abarcadora: no necesitamos suponer que todo evento tiene una causa, sino meramente que para eventos del tipo en cuestión, $F$, en el campo en cuestión, $C$, hay alguna condición necesaria y suficiente. Pero - y este es el lugar en el que necesitamos algo más que el determinismo o la uniformidad en general - también debemos presuponer que esta condición está constituida de alguna 
manera mediante alguna selección a partir de un rango restringido de factores posiblemente relevantes.

Es esta presuposición adicional la que hace surgir una duda acerca del uso de este método para hacer descubrimientos causales. En lo que respecta a la mera presuposición determinista de que el fenómeno en cuestión tiene alguna condición necesaria y suficiente, podemos conformarnos diciendo que esta es una [presuposición] que simplemente hacemos en todas las indagaciones de este tipo, y dejar que su justificación sea provista por la solución que eventualmente podamos encontrar para el problema general de la inducción. Pero la elección de un rango de factores posiblemente relevantes no puede ser dejada de lado tan fácilmente. Además, cuando más amplio sea el rango de factores posiblemente relevantes que admitamos, más difícil será defender la tesis de que se observa que $I_{1}$ y $N_{1}$ son similares respecto de todos los factores posiblemente relevantes con excepción de aquel factor, o el cúmulo indicado de factores, respecto de los que se ha observado que difieren. De manera alternativa, cuanto más estrechamente se restrinja el rango de factores posiblemente relevantes, más sencillo será defender la tesis de que hemos hecho una observación de la forma requerida, pero al mismo tiempo menos plausible será nuestra presuposición .

Sin embargo, esta dificultad se vuelve menos temible si consideramos a la presuposición y a la observación juntas. Queremos ser capaces de decir que no hay ninguna diferencia posiblemente relevante, además de la (o las) notadas, entre $I_{1}$ y $N_{1}$. No necesitamos formular una lista completa de factores posiblemente relevantes antes de hacer la observación. En la práctica, normalmente suponemos que un factor causalmente relevante estará cerca de la instancia del campo en o respecto del cual el efecto ocurre en $I_{1}$ o no ocurre en $N_{1}$, y que, o bien ocurrirá poco tiempo antes, o bien persistirá a lo largo del tiempo en el que el efecto tiene lugar en $I_{1}$, o podría haber ocurrido, pero no lo hizo, en $N_{1}$. Sin duda, en una aplicación más avanzada del Método de la Diferencia al interior de un cuerpo de conocimiento causal ya desarrollado, podemos restringir mucho más estrechamente el rango de factores posiblemente relevantes y podemos tomar pasos deliberados para excluir interferencias de nuestros experimentos; pero estoy sugiriendo que aún nuestro conocimiento causal más elemental y primitivo descansa sobre aplicaciones implícitas de este método, y el método espacio-temporal de restringir los factores 
posiblemente relevantes es el único disponible inicialmente. Y quizás eso es todo lo que necesitamos. Ciertamente, en términos de dicho método el observador podría decir, acerca del papel de tornasol, por ejemplo, "no puedo ver ninguna diferencia, además de la sumersión en este líquido, entre la situación en la que el papel se volvió rojo y aquella en la que no lo hizo, que pudiera ser relevante para este cambio".

Puede resultar instructivo comparar el Método de la Diferencia como un ideal lógico con cualquier aplicación efectiva suya. Si se supiera que la presuposición y la objeción son verdaderas, entonces la conclusión causal estaría establecida. En consecuencia, cualquier cosa que hable en favor, tanto de la presuposición como de la observación, habla igualmente en favor de la conexión causal. Sin dudas, nunca estamos en posición de decir que se sabe que son verdaderas, y que, por lo tanto, la conclusión está establecida; pero a menudo estamos en posición de decir que, dada la parte determinista de la presuposición, no podemos ver ningún respecto en el que no sean verdaderas (dado que no podemos ver ninguna diferencia que pudiera ser relevante entre $I_{1}$ y $\left.N_{1}\right)$ y, en consecuencia, que no podemos ver ninguna escapatoria respecto de la conclusión causal. En este sentido podemos decir, al menos, que una aplicación de este método confirma una conclusión causal: el observador ha buscado, pero no ha logrado encontrar, una escapatoria respecto de esta conclusión. ${ }^{28}$

\footnotetext{
${ }^{28}$ Una explicación de cómo el razonamiento inductivo eliminativo apoya conclusiones causales es dada por J. R. Lucas en el artículo citado en la nota 16 más arriba. Su explicación difiere de la mía en muchos detalles, pero concuerda con ella en el esquema general. Contrástese con esto los comentarios de von Wright, op. cit., p. 135: “... en la práctica científica normal tenemos que contar con la pluralidad antes que con la singularidad, y con la complejidad antes que con la simplicidad de las condiciones. Esto quiere decir que la forma más débil del Postulado Determinista, o la forma que puede ser considerada como una aproximación razonable a lo que se conoce comúnmente como la Ley de la Causación Universal, es prácticamente inútil como una premisa suplementaria o 'presuposición' de la inducción". Espero haber mostrado que este último comentario lleva a confusión.

Ha sido argumentado por A. Michotte (La perception de la causalité [Lovaina, 1946], traducida por T. R. y E. Miles como The Perception of Causality [Londres, 1963]) que tenemos en algunos casos una percepción o impresión inmediata de causación. Sus dos casos experimentales básicos son estos. En uno, un objeto $A$ se acerca a otro objeto $B$; al llegar a $B, A$ se detiene y $B$ comienza a moverse en la misma dirección; aquí el observador obtiene la impresión de que $A$ ha "lanzado" a $B$, que ha puesto a $B$ en movimiento. En el otro caso, $A$ continua moviéndose al llegar a $B$, y $B$ se mueve a la misma velocidad y en la misma dirección; aquí el observador obtiene la impresión de
} 
En la práctica no nos basamos tanto en observaciones singulares como esta explicación podría sugerir. Nos aseguramos de que fue la sumersión en este líquido lo que volvió rojo al papel de tornasol sumergiendo otros trozos de papel de tornasol y viéndolos, también, volverse rojos justo después de que son sumergidos. Esta repetición es efectiva porque sirve como una comprobación respecto de la posibilidad de que algún otro cambio relevante pudiera haber ocurrido, sin ser percibido, justo en el momento en el que el primer trozo de papel de tornasol era sumergido en el líquido. Después de algunos intentos será muy improbable que algún otro cambio relevante hubiera seguido ocurriendo justo cuando cada trozo de papel era sumergido (o incluso que hubiera habido una sucesión de distintos cambios relevantes en los momentos apropiados). Por supuesto, puede ser que haya algún otro cambio relevante (o conjunto de cambios relevantes) que continúa ocurriendo justo cuando cada papel es sumergido porque está conectado con la sumersión mediante lo que

que $A$ está llevando a $B$ consigo. En ambos casos, los observadores típicamente reportan que $A$ causó el movimiento de $B$. Michotte argumenta que es una característica esencial de las observaciones que dan lugar a esta impresión causal que debería haber dos movimientos distinguibles, el del "agente" $A$ y el del "paciente" $B$, pero también que es esencial que el movimiento del paciente sea en algún grado una copia o duplicado del del agente.

Esta parecería ser una explicación radicalmente diferente del modo en el que podemos detectar la causación mediante la observación de una única secuencia, pues de acuerdo con la concepción de Michotte, nuestra consciencia de la causación puede ser directa, perceptiva y no inferencial. Debe concederse que no solo la continuidad espacio-temporal, sino también la continuidad cualitativa entre causa y efecto (l'ampliation $d u$ mouvement) son ingredientes importantes en el concepto primitivo de causación; ellas pueden contribuir a la noción de "necesidad" causal; y ambas continuidades pueden a veces ser percibidas de manera directa. Pero es igualmente claro que en general no se requiere que estas continuidades sean aspectos observados o postulados de una secuencia causal, y que una secuencia que tiene estas continuidades puede no ser causal. Lo que se percibe en los ejemplos de Michotte no es ni necesario ni suficiente para la relación causal tal como la entendemos ahora, si bien puede haber jugado una parte importante en la génesis del concepto causal. Vale la pena notar que estos ejemplos también exhiben las características sobre las que se pone el acento en mi explicación. Ellas presentan al observador un campo causal aparentemente simple y aislado, dentro del cual ocurre un cambio notorio, el comienzo del movimiento de $B$. El acercamiento de $A$ es la única diferencia posiblemente relevante observada entre los momentos en que $B$ está estacionario y en los que $B$ comienza a moverse. Si el comienzo del movimiento de $B$ tiene una causa, entonces el acercamiento de $A$ es un candidato adecuado, y ninguna otra cosa que se le permite ver o se le anima a suponer al observador lo es. De este modo, estos ejemplos podrían también dar lugar a una captación [awareness] inferencial de la causación, si bien es cierto que otros ejemplos que podrían hacer esto igualmente bien no lograrían, y en los experimentos de Michotte no logran, producir una impresión directa de causación. 
Mill llama "algún hecho de causación". ${ }^{29} \mathrm{Si}$ es así, entonces este otro cambio relevante puede ser considerado como parte de un cúmulo de factores que pueden ser agrupados bajo el título "la sumersión del papel en este líquido", tomando esto en un sentido amplio, pudiendo incluir ítems distintos de la entrada efectiva del papel dentro del líquido. Pero si esto no es así, entonces sería una mera coincidencia si este otro cambio relevante siguiera ocurriendo justo cuando cada trozo de papel era sumergido, o si hubiera una sucesión de cambios relevantes en los momentos apropiados. La hipótesis de que tales coincidencias han continuado se volverá rápidamente implausible, por más que no pueda ser falsada de modo concluyente. ${ }^{30}$ Es un punto importante que no es la repetición como tal lo que sustenta la conclusión de que la sumersión causa el volverse rojo, sino la repetición de una secuencia que, en cada ocasión singular, ya es prima facie de tipo causal. La repetición tiende a disconfirmar el conjunto de las hipótesis que explican, cada una de ellas, una única secuencia de una sumersión seguida de un volverse rojo como una mera coincidencia, y por contraste confirma la hipótesis de que en cada secuencia singular semejante la sumersión está conectada causalmente con el cambio de color.

El análisis ofrecido aquí del Método de la Diferencia tiene esta consecuencia curiosa: al utilizar este método tendemos a usar la palabra "causa" en distintos sentidos en distintos estadios. En la presuposición, se dice que el fenómeno F tiene alguna "causa", con lo que se quiere decir, alguna condición necesaria y suficiente; pero la "causa" efectivamente encontrada - $A$ en nuestro ejemplo formal - puede ser solo una condición INIS. Pero necesitamos suponer que algo es a la vez necesario y suficiente para $F$ en $C$ para ser capaces de concluir que $A$ es al menos una condición INIS, que es un momento en una condición suficiente mínima que estaba presente, y que era necesaria post factum.

\footnotetext{
${ }^{29}$ Por ejemplo, en el Quinto Canon, A System of Logic, Libro III, Capítulo VIII, § 6.

${ }^{30} \mathrm{Cf}$. J. R. Lucas, op. cit., p. 53: "Podría ser que estaban teniendo lugar dos procesos completamente independientes, y que estábamos obteniendo una concomitancia constante sin ninguna razón, con la excepción del hecho fortuito de que los dos procesos se iban desarrollando al mismo tiempo. Si esto fuera así, una perturbación arbitraria en uno de ellos mostrará la independencia del otro. Si una perturbación arbitraria en uno es seguida por una alteración correspondiente en el otro, siempre podría tratarse de una coincidencia genuina ... Pero argumentar esto persistentemente es hacer la misma extensión ilícita con 'coincidencia' que algunos fenomenalistas hacen con 'ilusión'... Ya no es más una posibilidad práctica la que estamos eliminando, sino una duda cartesiana”.
} 


\section{Falsación de enunciados incompletos.}

Una posible objeción a esta explicación es que las leyes con lagunas y los enunciados singulares utilizados aquí son tan incompletos que tienen una garantía interna frente a la falsación y que, por lo tanto, no son siquiera enunciados científicos genuinos. Sin embargo, no es un criterio satisfactorio de los enunciados científicos que estén expuestos a una falsación concluyente: lo importante es que tratar un enunciado como una hipótesis científica implica tratarlo de un modo tal que se permita que la evidencia hable en su contra. Y hay modos en los que puede permitirse, y se permite, que la evidencia hable en contra de un enunciado que asevera que algo es una condición INIS. Supongamos, por ejemplo, que usando el esquema con $I_{1}$ y $N_{1}$ presentado en $\S 5$ más arriba hemos concluido que $A$ es al menos una condición INIS de $F$ - tomando esto a la vez como un enunciado causal singular acerca de un campo individual $C_{1}$ y como una ley incompleta acerca del campo general $C$. Ahora supongamos que un examen más cercano muestra que algún otro factor, no notado anteriormente, digamos $K$, estaba presente en $I_{1}$ y ausente de $N_{1}$, y que también descubrimos (o construimos experimentalmente) otros casos $I_{2}$ y $N_{2}$ tales que la evidencia observacional es ahora de la forma:

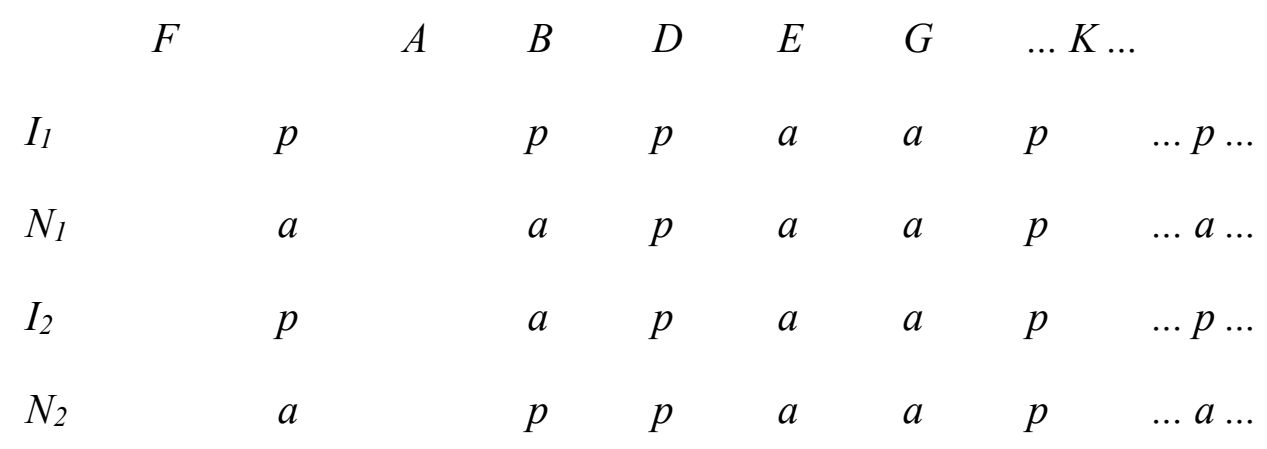

Aquí $N_{2}$ muestra que para cualquier $X$ que no contiene $K, A X$ no es suficiente: de modo que $X$ debe contener $K$. Pero cualquier $X$ que contiene a $K$ está presente en $I_{2}$, y puede por lo tanto, ser suficiente para $F$ por sí mismo, $\sin A$. Esta evidencia no falsifica de manera concluyente la hipótesis de que $A$ es una condición INIS como se afirma más arriba, pero 
elimina toda la razón que la evidencia previa nos dio para esta conclusión. Observaciones con este patrón hablarían en contra de esta conclusión, y nos conducirían a reemplazar la opinión de que $A$ causa $F$, y causó $F$ en $I_{1}$, por la opinión de que $K$ causa $F$, y causó $F$ tanto en $I_{1}$ como en $I_{2}$, con $A$ ni siquiera constituyendo una parte indispensable de la condición suficiente que estaba presente en $I_{1}$. (Un tratamiento más completo de este tipo de evidencia adicional requeriría explicaciones del Método del Acuerdo [Method of Agreement] y del Método Conjunto [Joint Method] paralelas a la [explicación] del Método de la Diferencia dada en $§ 5$.

Sigue siendo verdadero que algunas de las afirmaciones hechas mediante enunciados causales singulares y leyes causales, tal como son analizadas aquí - esto es, afirmaciones de que algún factor es al menos una condición INIS del efecto - no son falsables de manera concluyente. Pero las leyes causales ordinarias y los enunciados causales singulares no son falsables de manera concluyente, como mostrará una consideración directa. Es un mérito de la explicación ofrecida aquí, no una dificultad suya, que reproduzca este aspecto del conocimiento causal ordinario. ${ }^{31}$

\section{Dependencia funcional y variación concomitante.}

Tal como mencioné en $\S 3$, los enunciados causales a veces refieren, no a relaciones de necesidad y suficiencia, ni a ninguna relación más compleja basada en éstas, tal como la de ser una condición INIS, sino a relaciones de dependencia funcional. Esto es, el efecto y los posibles factores causales son cosas que pueden variar en magnitud, y la causa de algún efecto $F$ es aquello de cuya magnitud depende funcionalmente la magnitud de $F$. Pero los enunciados causales de este tipo pueden ser expandidos y analizados en una explicación paralela a aquella que hemos dado de los enunciados causales de los tipos anteriores. De nuevo, hablamos de un campo, individual o general, en relación con el cual se da una cierta dependencia funcional. También, podemos hablar de la causa total, del conjunto completo de factores de cuya magnitud depende completamente la magnitud de $F$, dado el campo $C$ : esto es, las variaciones de $F$ en $C$ son cubiertas completamente por

\footnotetext{
${ }^{31}$ Esto fue señalado por D. C. Stove.
} 
una fórmula que es una función de las magnitudes de todos los factores en este "conjunto completo", y solo de éstos. Esta causa total es análoga a una condición necesaria y suficiente. Puede ser distinguida de cada uno de los factores que la componen, cada uno de los cuales es causalmente relevante para el efecto, pero no es la causa total de sus variaciones: cada una de estas causas parciales es análoga a una condición INIS.

El problema de encontrar una causa en este nuevo sentido requeriría, para su solución completa, la realización de dos tareas. Deberíamos, tanto identificar todos los factores en esta causa total, como descubrir de qué modo el efecto depende de ellos - esto es, descubrir la ley de dependencia funcional del efecto respecto de la causa total, o las ecuaciones diferenciales parciales que lo relacionan con cada una de las causas parciales. La primera - pero solo la primera - de estas dos tareas puede ser realizada mediante lo que es realmente el Método de la Variación Concomitante, desarrollado en un estilo análogo a aquél en el que se desarrolló el Método de la Diferencia en $\S 5$. Esto es, suponemos que hay algo de lo que depende funcionalmente la magnitud de $F$ en $C$, y que hay un conjunto restringido de factores posiblemente relevantes; entonces, si mientras se mantienen constantes todos los otros factores posiblemente relevantes, un factor, digamos $A$, varía, y $F$ también varía, se sigue que $A$ es al menos una causa parcial, que es uno de los factores efectivamente relevantes. Es esta relación lo que se afirma comúnmente mediante enunciados de formas tales como " $A$ afecta a $F$ ” y “En esta ocasión $A$ afectó a $F$ ”. Algunos de nuestros enunciados causales, singulares o generales, tienen precisamente esta fuerza, y todo lo que estoy intentando mostrar aquí es que estos enunciados pueden apoyarse mediante razonamientos que siguen los lineamientos del Método de Variación Concomitante, desarrollado de manera análoga a como se desarrolló en $\S 5$ el Método de la Diferencia. Así como presupusimos allí que había alguna condición necesaria y suficiente, y descubrimos algo que es al menos una condición INIS al combinar esta suposición con nuestras observaciones, presuponemos aquí que hay alguna causa total y descubrimos así algo que es al menos una causa parcial. Sin embargo, una explicación completa del Método de la Variación Concomitante involucraría el examen de muchos otros casos además del esbozado aquí. ${ }^{32}$ Para nuestro propósito presente, solo necesitamos

\footnotetext{
${ }^{32} \mathrm{He}$ dado una explicación más acabada de este método en el artículo citado en nota 25.
} 
notar que existe tanto esta parte de dependencia funcional del concepto de causación como la parte de presencia-o-ausencia, y en verdad que ésta última puede ser considerada como un caso límite especial de la primera, ${ }^{33}$ pero que las dos partes son sistemáticamente análogas entre sí, y que nuestro conocimiento de las relaciones causales tanto singulares como generales de estos dos tipos pueden ser explicados de acuerdo con principios correspondientes.

\section{La dirección de la causación.}

Esta explicación de la causación está todavía incompleta, en la medida en que no se ha dicho aún nada acerca de la dirección de la causación, acerca de lo que distingue que $A$ cause $F$ de que $F$ cause $A$. Esta es una cuestión difícil, y está conectada con la cuestión igualmente difícil de la dirección del tiempo. No puedo esperar resolverla completamente aquí, pero enunciaré algunas de las consideraciones relevantes. ${ }^{34}$

En primer lugar, parece que hay una relación que puede ser llamada prioridad causal, y que parte de lo que se quiere decir mediante " $A$ causó $F$ ” es que esta relación se da en una dirección entre $A$ y $F$ y no en la otra. En segundo lugar, esta relación no es idéntica con la prioridad temporal; es concebible que hubiera evidencia para un caso de causación "hacia atrás", para [un caso en que] $A$ fuera causalmente anterior a $F$ mientras que $F$ era temporalmente anterior a $A$. La mayoría de nosotros cree, y creo que con buenas razones, que la causación hacia atrás no ocurre, de modo que podemos usar, y normalmente de hecho usamos, el orden temporal para limitar las posibilidades acerca del orden causal; pero la conexión entre los dos es sintética. En tercer lugar, podría objetarse al análisis de "necesario" y "suficiente" ofrecido en $\S 4$ más arriba que omite toda referencia al orden causal, mientras que nuestros usos más comunes de "necesario" y "suficiente" en contextos

\footnotetext{
${ }^{33}$ Cf. J. R. Lucas, op. cit., p. 65.

${ }^{34} \mathrm{Tal}$ como fue mencionado en la n. 21, la quinta dificultad y el quinto refinamiento de Scriven se ocupan de este punto (op. cit., pp. 411-412), pero su respuesta me parece inadecuada. Lucas se refiere brevemente al tema (op. cit., pp. 51-53). El problema de la asimetría temporal es discutido, por ejemplo, por J. J. C. Smart, Philosophy and Scientific Realism (Londres, 1963), pp. 142-148, y por A. Grünbaum en el artículo citado en nota 36 más abajo.
} 
causales incluyen una referencia semejante. Así, " $A$ es (causalmente) suficiente para $B$ " dice "Si $A$, entonces $B$, y $A$ es causalmente anterior a $B$ ", pero " $B$ es (causalmente) necesaria para $A$ " no es equivalente a esto: dice "Si $A$, entonces $B$, y $B$ es causalmente anterior a $A$ ". Sin embargo, es más simple usar "necesario" y "suficiente" en sentidos que excluyen esta prioridad causal, e introducir de manera separada la afirmación de prioridad en nuestras explicaciones de " $A$ causó $F$ " y " $A$ causa $F$ ". En cuarto lugar, si bien " $A$ es (al menos) una condición INIS de $F$ " no es sinónima de " $F$ es (al menos) una condición INIS de $A$ ", esta diferencia de significado no puede agotar la relación de prioridad causal. Si la agotara, la dirección de la causación sería una cuestión trivial, puesto que, dado que hay alguna condición necesaria y suficiente de $A$ en el campo, puede probarse que si $A$ es (al menos) una condición INIS de $F$, entonces $F$ es también (al menos) una condición INIS de $A$ : podemos construir una condición suficiente mínima de $A$ en la que $F$ sea un momento. ${ }^{35}$

En quinto lugar, se sugiere a menudo que la dirección de la causación está conectada con la controlabilidad. Si hay una relación causal entre $A$ y $B$, y podemos controlar $A \sin$ hacer uso de $B$ para hacerlo, y la relación entre $A$ y $B$ se mantiene, entonces decidimos que $B$ no es causalmente anterior a $A$ y, en general, que $A$ es causalmente anterior a $B$. Pero esto significa sólo que si un caso de prioridad causal es conocido, podemos usarlo para determinar otros: nuestro rechazo de la posibilidad de que $B$ sea causalmente anterior a $A$ se basa en nuestro conocimiento de que nuestra acción es causalmente anterior a $A$, y la pregunta de cómo conocemos esto último, y aún la pregunta de qué es la prioridad causal, tiene aún que ser respondida. De manera similar, si uno de los tipos de eventos causalmente relacionados, digamos, $A$, puede ser aleatorizado, de modo que ocurrencias de $A$ son o bien no causadas en ningún sentido, o son causadas por algo que entre en este campo causal sólo de esta manera, mediante el hecho de que causa a $A$, podemos rechazar tanto la posibilidad de que $B$ sea causalmente anterior a $A$ como la posibilidad de que alguna causa común sea anterior tanto respecto de $A$ como separadamente respecto de $B$, y podemos de nuevo concluir que $A$ es causalmente anterior a $B$. Pero esto aún sólo significa que podemos inferir la prioridad causal en un lugar si primero sabemos que está ausente en otro lugar.

\footnotetext{
${ }^{35}$ Estoy en deuda con uno de los árbitros por corregir una expresión incorrecta de este punto en una versión anterior.
} 
Es verdad que nuestro conocimiento de la dirección de la causación en casos ordinarios está basada de este modo en lo que hallamos que es controlable, y en lo que o bien hallamos que es aleatorio o hallamos que podemos aleatorizar; pero esto no puede ser tomado como proveyendo sin circularidad una explicación completa ya sea de lo que queremos decir con prioridad causal o de cómo es que sabemos acerca de ella.

Una sugerencia presentada por Popper acerca de la dirección del tiempo parece relevante aquí. ${ }^{36} \mathrm{Si}$ una piedra es arrojada en una pileta, la entrada de la piedra explicará las ondas circulares en expansión. Pero el proceso inverso, con ondas circulares que se contraigan "demandaría un gran número de generadores de ondas coherentes y distantes cuya coherencia, para ser explicable, debería mostrarse ... que se originan en un centro". Esto es, si $B$ es una ocurrencia que involucra un cierto tipo de "coherencia" entre una gran cantidad de ítems separados, mientras que $A$ es un evento singular, y $A$ y $B$ están conectados causalmente, $A$ explicará a $B$ de un modo en que $B$ no explicará a $A$, a menos que algún otro evento singular, digamos $C$, explique con anterioridad la coherencia en $B$. Tales ejemplos nos dan una dirección de explicación, y puede ser que esta sea la base, o parte de la base, de la relación que he denominado prioridad causal.

\section{Conclusiones.}

Aún si Mill estaba equivocado al pensar que la ciencia consiste fundamentalmente en conocimiento causal, difícilmente puede negarse que tal conocimiento es un elemento indispensable en la ciencia, y que vale la pena investigar el significado de enunciados causales y las maneras en las que podemos llegar al conocimiento causal. Las relaciones causales generales están ente los ítems que un tipo más avanzado de teoría científica explica, y por el éxito en explicar las cuales ésta es confirmada. Las aserciones causales singulares están involucradas en casi todo reporte de un experimento: hacer tal y cual cosa produjo un efecto tal y cual. Los materiales son identificados normalmente por sus propiedades causales: para reconocer a algo como un trozo de cierto material, por lo tanto,

\footnotetext{
36“"The Arrow of Time”, Nature, vol. 177 (1956), p. 538; también vol. 178, p. 382 y vol. 179, p. 1297.
} 
debemos establecer aserciones causales singulares acerca de él, que este objeto afectó a aquel otro, o fue afectado por él, de tal y cual manera. Las aserciones causales forman parte tanto de los resultados como de los procedimientos de la investigación científica.

La explicación que he ofrecido de la fuerza de varios tipos de enunciados causales concuerda tanto con nuestra comprensión informal de ellos como con las explicaciones formuladas por otros escritores: al mismo tiempo es suficientemente formal como para mostrar cómo tales enunciados pueden ser corroborados por observaciones y experimentos, y así arrojar nueva luz sobre las cuestiones filosóficas acerca de la naturaleza de la causalidad y de la explicación causal, y sobre el estatus del conocimiento causal.

Un punto importante es que, dejando de lado la cuestión de la dirección de la causación, el análisis ha sido formulado enteramente dentro de los límites de lo que podemos seguir llamando una teoría regularista de la causación, en tanto que las leyes causales involucradas en ella no son más que proposiciones universales simples, si bien sus términos pueden ser complejos y quizás estén especificados de modo incompleto. A pesar de esta limitación, he sido capaz de dar una explicación del significado de los enunciados acerca de secuencias causales singulares, sin importar si una secuencia tal es o no es de un tipo que vuelve a ocurrir con frecuencia: la repetición no es esencial para la relación causal, y la regularidad no desaparece aquí en el mero hecho de que esta secuencia singular ha ocurrido. Por cierto, ha sido a menudo reconocido que la teoría regularista podría dar cuenta de las secuencias singulares si, digamos, una secuencia única pudiera ser explicada como la resultante de un número de leyes cada una de las cuales fue ejemplificada en muchas otras secuencias; pero mi explicación muestra cómo un enunciado causal singular puede ser interpretado, y cómo puede mostrarse que la secuencia correspondiente es causal, aún si las leyes completas correspondientes no son conocidas. Muestra incluso cómo una secuencia única puede ser reconocida directamente como causal.

Una consecuencia de esto es que ahora se vuelve posible reconciliar lo que parecían ser concepciones divergentes acerca de la naturaleza de la explicación histórica. Estamos acostumbrados a contrastar la teoría de la "ley de cobertura" adoptada por Hempel, Popper y otros con las posiciones de críticos tales como Dray y Scriven, que han argumentado que 
las explicaciones y los enunciados causales en historia no pueden ser así asimilados a los patrones aceptados en las ciencias físicas. ${ }^{37}$ Pero mientras que mi análisis básico de los

${ }^{37}$ Véase, por ejemplo, C. G. Hempel, "The Function of General Laws in History", Journal of Philosophy, vol. 39 (1942), reimpreso en Readings in Philosophical Analysis, ed. por H. Feigl y W. Sellars (Nueva York, 1949), pp. 459-471; C. G. Hempel y P. Oppenheim, "Studies in the Logic of Explanation”, Philosophy of Science, vol. 15 (1948), reimpreso en Readings in the Philosophy of Science, ed. por H. Feigl y M. Brodbeck (Nueva York, 1953), pp. 319-352); K. R. Popper, Logik der Forschung (Vienna, 1934), traducido como The Logic of Scientific Discovery (Londres, 1959), pp. 59-60, también The Open Sociey (Londres, 1952), vol. II, p. 262; W. Dray, Laws and Explanation in History (Oxford, 1957); N. Rescher, "On Prediction and Explanation", British Journal for the Philosophy of Science, vol. 9 (1958), pp. 281; varios artículos en Minnesota Studies in the Philosophy of Science, vol. III, ed. por H. Feigl y G. Maxwell (Minneapolis, 1962); A. Grünbaum, "Temporally-asymmetric Principles, Parity between Explanation and Prediction, and Mechanism versus Teleology", Philosophy of Science, vol. 29 (1962), pp. 146-170.

Las críticas de Dray de la teoría de las leyes de cobertura incluye las siguientes: no podemos enunciar la ley usada en una explicación histórica sin hacerla tan vaga que resulte vacía (op. cit., especialmente pp. 24-37) o tan compleja que cubre solo un único caso y es por ese motivo trivial (p. 39); el historiador no llega a la tarea de explicar un evento con una cantidad suficiente de leyes ya formuladas y validadas empíricamente (pp. 42-43); los historiadores no necesitan reemplazar el juicio acerca de casos particulares con una deducción a partir de leyes validadas empíricamente (pp. 51-52). Será claro que mi explicación resuelve cada una de estas dificultades. Grünbaum traza una importante distinción entre (1) una asimetría entre explicación y predicción respecto de los fundamentos a partir de los cuales afirmamos saber que el explanandum es verdadero, y (2) una asimetría respecto de la relación lógica entre el explanans y el explanandum; él cree que sólo se da el primer tipo de asimetría. Sugiero que mi explicación del uso de las leyes con lagunas esclarecerá tanto el sentido en que Grünbaum está en lo correcto (dado que una explicación y una predicción tentativas pueden usar leyes que tienen lagunas de manera similar que están relacionadas de manera similar a las condiciones iniciales conocidas y al resultado) y el sentido en que, en un caso semejante, podemos contrastar una explicación enteramente satisfactoria con una predicción meramente tentativa. Scriven (en su formulación más reciente, la reseña citada en la nota 10 más arriba) dice que "a menudo aislamos un factor como una causa excluyendo otras causas posibles. Esto es simple - pero desastroso para la teoría de la explicación que apela a las leyes de cobertura, porque podemos eliminar causas solo para algo que sabemos que ha ocurrido. Y si los fundamentos para nuestra explicación de un evento tienen que incluir el conocimiento de la ocurrencia de ese evento, no pueden ser usados (sin circularidad) para predecir la ocurrencia de ese evento" (p. 414). Esto es, la observación de este evento en estas circunstancias puede ser una parte vital de la evidencia que justifica la explicación causal particular que damos de este evento: puede ella misma avanzar bastante en el establecimiento la ley elíptica en relación con la cual lo explicamos (como mostré en $\S 5$ ), mientras que una ley usada para predicción no puede descansar de esta manera en la observación del evento predicho. Pero como mi explicación también muestra, esto no introduce una asimetría del segundo tipo de Grünbaum, y por lo tanto no es desastrosa para la teoría de la ley de cobertura. 
enunciados causales singulares en los $\S \S 1$ y 2 concuerda estrechamente con el de Scriven, argumenté en el $\S 4$ que este análisis puede ser desarrollado en términos de proposiciones universales complejas y elípticas, y esto quiere decir que cada vez que tenemos un enunciado causal singular seguiremos teniendo una ley de cobertura, si bien una compleja y quizás elíptica. También, he mostrado en $\S 5$ e indicado brevemente, para las variantes de dependencia funcional, en $\S 7$, que la evidencia que fundamenta los enunciados causales singulares también fundamenta los enunciados causales generales o leyes de cobertura, si bien nuevamente sólo unas que son complejas y elípticas. Hempel reconoció hace mucho que las explicaciones históricas pueden ser interpretadas como dando "esbozos de explicación" incompletos, en vez de lo que consideraría como explicaciones completas, que requerirían leyes de cobertura completamente especificadas, y que tales esbozos también son comunes fuera de la historia. Pero en estos términos lo que estoy diciendo es que los esbozos de explicación y las leyes elípticas relacionadas son a menudo todo lo que podemos descubrir, y que ellos desempeñan un papel en todas las ciencias, que pueden ser fundamentados y aún establecidos sin estar completos, y no cumplen meramente el papel de preliminares o resúmenes de explicaciones deductivas completas. Si modificamos la noción de una ley de cobertura para admitir leyes que no solo son complejas sino que son sólo conocidas de una manera elíptica, la teoría de leyes de cobertura puede acomodar muchos de los puntos que se han formulado como críticas a ella, a la vez que se preserva la similitud estructural de la explicación en historia y en las ciencias físicas. En esta controversia, un punto en cuestión ha sido la simetría de explicación y predicción, y mi explicación puede ayudar a resolver esta disputa. Muestra, en concordancia con lo que Scriven ha argumentado, cómo la ocurrencia efectiva de un evento en las circunstancias observadas $[. .$.$] puede ser una parte vital de la evidencia que fundamenta una explicación$ de ese evento, que muestra que fue $A$ lo que causó $F$ en esa ocasión. Una predicción, por otra parte, no puede descansar en la observación del evento predicho. Además, la ley lagunosa que es suficiente para una explicación no será suficiente para una predicción (o para una retrodicción): un enunciado de las condiciones iniciales junto con una ley lagunosa no va a implicar la aserción de que un resultado específico va a ocurrir, si bien por supuesto una ley semejante puede ser, y a menudo es, usada para hacer predicciones tentativas cuyo fracaso no hablará necesariamente en contra de la ley. Pero el 
reconocimiento de estas diferencias entre predicción y explicación no afecta la teoría de la ley de cobertura modificada por el reconocimiento de leyes elípticas.

Si bien lo que he dado es primariamente una explicación de la causación física, puede ser indirectamente relevante para la comprensión de la acción humana y la causación mental. Se sugiere a veces que nuestra capacidad de reconocer una ocurrencia singular como un caso de causación mental es una característica que distingue la causación mental de la física o "humeana". ${ }^{38}$ Pero esta sugerencia surge del uso de una explicación regularista demasiado simple de la causación física. Si primero vemos claramente lo que queremos decir mediante enunciados causales singulares en general, y cómo podemos fundamentar un enunciado semejante mediante la observación de la secuencia singular misma, aún en un caso físico, seremos capaces de contrastar mejor con esto nuestra percepción [awareness] de las causas mentales, y ver si las últimas tienen algunas características realmente distintivas.

Esta explicación también arroja luz tanto sobre la forma como sobre el estatus del “principio causal", la presuposición determinista que es usada en cada aplicación de los métodos de eliminación inductiva. Estos métodos no tienen por qué presuponer el determinismo en general, sino sólo que cada fenómeno específico investigado mediante ese método es determinista. Más aún, requieren no sólo que el fenómeno tenga alguna causa, sino que debería haber alguna restricción del rango de factores relevantes posibles (al menos a los que son espaciotemporalmente cercanos, como se explica en $\S 5$ ). Ahora bien, el principio causal general, según el cual todo evento tiene alguna causa, es tan general que es particularmente difícil tanto confirmarlo como falsarlo [disconfirm], y podríamos estar tentados o bien a reclamar para él algún estatus a priori, o convertirlo en

\footnotetext{
${ }^{38}$ Véase, por ejemplo, G. E. M. Anscombe, Intention (Oxford, 1957), especialmente p. 16; J. Teichmann, "Mental Cause and Effect", Mind, vol. 70 (1961), pp. 36-52. Teichmann habla (p. 36) de "la diferencia entre ellas y secuencias ordinarias (o 'humianas') de causa y efecto", y dice (p. 37) “a veces está bien que la persona que parpadea diga de modo absolutamente dogmático que la causa es tal y tal, y decir esto con independencia de su conocimiento de cualquier correlación previamente establecida", y nuevamente, "si el ruido es una causa, parece ser una de la que se sabe que lo es de un modo especial. Parece que, mientras que es necesario que un observador tenga conocimiento de una correlación previamente establecida entre los sonidos y los saltos de Smith antes de que pueda aseverar que uno causa al otro, no es necesario que Smith mismo lo tenga".
} 
una presuposición metafísica absoluta, o rechazarlo como vacuo. Pero la suposición específica de que este fenómeno tiene alguna causa basada de un modo u otro en factores extraídos de este rango, o aún que este fenómeno tiene alguna causa cercana, está mucho más abierta a confirmación y falsación: en verdad, la primera puede ser falsada de manera concluyente mediante la observación de una instancia positiva de $F$ y un caso negativo en que $F$ no ocurre, pero donde cada uno de los factores en el rango dado está o bien presente en ambos casos o bien ausente de ambos. Esta explicación, entonces, nos habilita a considerar la presuposición como algo a ser confirmado o falsado empíricamente. Al mismo tiempo muestra que debe haber algún principio de la confirmación de hipótesis distinta de los métodos eliminativos mismos, dado que cada método semejante descansa sobre una presuposición empírica. 